\title{
Forest fire management expenditures in Canada: 1970-2013
}

\author{
B.J. Stocks ${ }^{1}$ and David L. Martell ${ }^{2}$
}

\begin{abstract}
Fire plays a vital role in forest management in Canada and the cost of fire management varies significantly both spatially and temporally. We present the fixed (pre-suppression) and variable (suppression) expenditures incurred by Canadian forest and wildland fire management agencies over the period 1970-2013. We describe how the data was compiled, display it in a graphical format, present the results of our preliminary analysis of that data and discuss those results and the need to investigate both fire management productivity and the factors that influence it. The data is available in a public repository where it can be readily accessed by others who wish to explore it in further detail.
\end{abstract}

Key words: wildland fire, wildfire, fire suppression, fire management expenditures

\section{RÉSUMÉ}

Les feux de forêt jouent un rôle essentiel en matière ddans l’aménagement forestier au Canada et les coûts de suppression des feux varient grandement selon lendroit et le tempstant sur le plan spatial que temporel. Nous présentons les coûts fixes (présuppressionprésuppression) et les coûts variables (suppression) obtenus encourus par ldes organismes canadiens de contrôle des feux de forêt et des feux de broussaillesen zone de protection totale et partielle pour la période allant de 1970 à 2013 . Nous décrivons comment ces données ont été compilées, puis transposées sous forme de graphiques, pour poursuivre avec une présentation de nos analyses préliminaires de ces données et d'une discussion des résultats obtenus et de la nécessité détudier tant la productivité au niveau du contrôle des feux que les facteurs qui linfluencel'influencent. Les données peuvent être consultées dans un registre d’accès public par toute personne voulant désireuse de les étudier plus en détail.

Mots clés : feux de broussaille, feux de forêt, feux de végétation, suppression des feux, coûts de suppression des feux

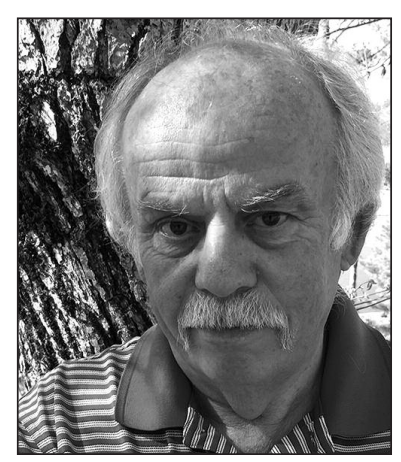

B.J. Stocks

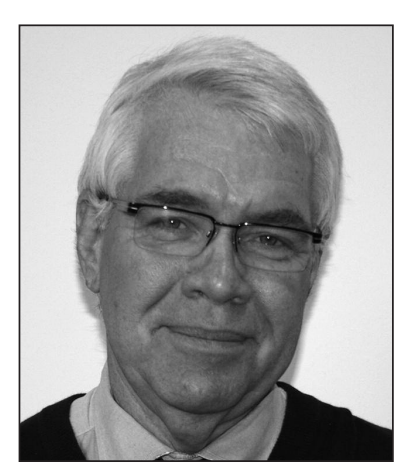

David L. Martell

\section{Introduction}

In his foreword to Stephen Pyne's (2007) history of forest fire management in Canada, Graeme Wynn noted that, in the final decades of the nineteenth century, rising concern about the loss of timber due to fire and the depletion of North American forest reserves led to the creation of branches of government dedicated to managing Canada's forests, and that "fire quickly became the main focus of their attention". Organized forest fire management grew in much of Canada in the early 1900s in response to large wildfires that swept across forested landscapes and settlement areas and caused widespread loss of lives and property. Growing public and political awareness of the need to protect both communities and an expanding forest industry resulted in the development of forest fire control organizations with policies aimed primarily at total fire exclusion. Subsequent increased access to and utilization of forested areas for both recreation and industrial purposes resulted in increased forest fire incidence, along with expanding fire management capacity.

By the mid-1900s all Canadian provinces, along with the Yukon and Northwest Territories developed comprehensive fire protection programs, the historical development of which are described in Pyne (2007). Canadian fire management agencies have continued to evolve to meet changing demands, but significant wildfire events are still common, as evidenced by the 2003 fires in British Columbia and the 2011 Slave Lake Fire in Alberta which resulted in insured losses exceeding $\$ 1$ billion and the destruction of approximately 800 homes and businesses. More recently, 4.6 million ha and 3.9 million ha burned, primarily in western Canada, in 2014 and 2015 respectively. Over the past decade (2006-2015) Canada has averaged 6863 fires and 2.6 million ha burnt annually, and the average annual national fire management expenditures exceeded $\$ 800$ million during this period.

Fire is a natural ecosystem process but it poses significant threats to public safety, property and forest resources, and fire managers must balance such losses with the beneficial ecological impacts of fire. This paper focuses on fire management costs. Our objectives are to: 1) document recent fire expendi-

\footnotetext{
${ }^{1}$ B.J. Stocks Wildfire Investigations Ltd, Sault Ste. Marie, Ontario, Canada P6A 4V4

${ }^{2}$ Faculty of Forestry, University of Toronto, 33 Willcocks Street, Toronto, Ontario, Canada, M5S 3B3
} 
tures; 2) present the results of our preliminary analysis of that data; and, 3) make the data available in a digital format in the hope that others will join us in investigating some of the many important economic aspects of fire management that we, and others before us, have identified as being essential for sound fire management in Canada.

We begin with a brief overview of Canada's forest and wildland fire management system from an economic perspective and then introduce our readers to the basic principles of fire economics to illustrate the need to and importance of documenting agency expenditures over time. We then describe how we compiled fire management expenditure data for all Canadian fire management agencies for the years 1970-2013. This is followed by a description of the results of our analysis of that data. We conclude with a discussion of our findings, suggestions on how we might move forward, and our conclusions.

\section{Forest and wildland fire management in Canada}

With the exception of national parks and a small amount of land under the jurisdiction of the Federal Government and municipalities, forest and wildland fire management in Canada is a provincial and territorial government responsibility. Each of the ten provinces and two of the three territories have a fire management agency. Parks Canada is responsible for fire management in national parks and the Department of National Defence is responsible for fire management on military bases. Fig. 1 illustrates the significant variation of both fire occurrence (the left hand bars associated with each agency) and area burned (the corresponding right hand bars) across Canada. The average number of fires and area burnt per year across all agencies for 1970-2013 was 8467 fires and 2.1 million hectares.

When viewing this graph it is important to recognize that both the size of the area over which each agency is responsible for fire management differs by agency and the level of protection or extent to which fires are suppressed varies spatially within most agencies. One factor that contributes to the within-agency variation is that Canada has large areas of remote northern forest where fire is largely permitted to play its natural role in ecosystem structure and maintenance. These natural fires, which generally only receive suppression action if and when they threaten public safety, property, vital infrastructure or forest resources, typically account for about $50 \%$ of the total area burned nationally. Although some agencies with modified fire suppression policies have large areas burnt (e.g., $\mathrm{YK}^{3}, \mathrm{NT}, \mathrm{SK}, \mathrm{MB}, \mathrm{QC}$ and $\mathrm{ON}$ ), it is clear that BC, $A B, Q C$ and $O N$ deal with the most significant fire loads (in terms of fire occurrence) across the country. $\mathrm{BC}$ and $\mathrm{AB}$ do not have modified fire suppression zones.

The Canadian Wildland Fire Strategy (CWFS) was developed in 2006 under the auspices of the Canadian Council of Forest Ministers (CCFM) in response to rising concern that a number of emerging issues were undermining the effectiveness of Canada's fire management programs and compromising the ability of Canadian fire managers to deliver their programs as effectively as they had in the past (CCFM 2006). The CWFS, which was approved by all provincial and territorial governments, noted that despite close to a century of success in managing fire in a manner that permitted some natural fire in designated areas while vigorously protecting human life and property, fire management in Canada was approaching a crossroads. Climate change-driven forest fire and forest health issues were projected to combine with an expanding wildland-urban interface (WUI) and a declining, more costly wildland fire suppression capability, to create unprecedented fire impacts across Canada in the near future. The authors of the CWFS recognized that, given these factors, maintaining recent levels of fire protection success would be economically and physically impossible, and called for a new accommodation with wildland fire with an emphasis on adaptation and a realization that fire would likely assume its natural role across more of the Canadian landscape in future years. One of the authors of this paper was asked to document the extent to which fire management costs had been increasing. This paper describes how that data was compiled and the results of our preliminary analysis of it.

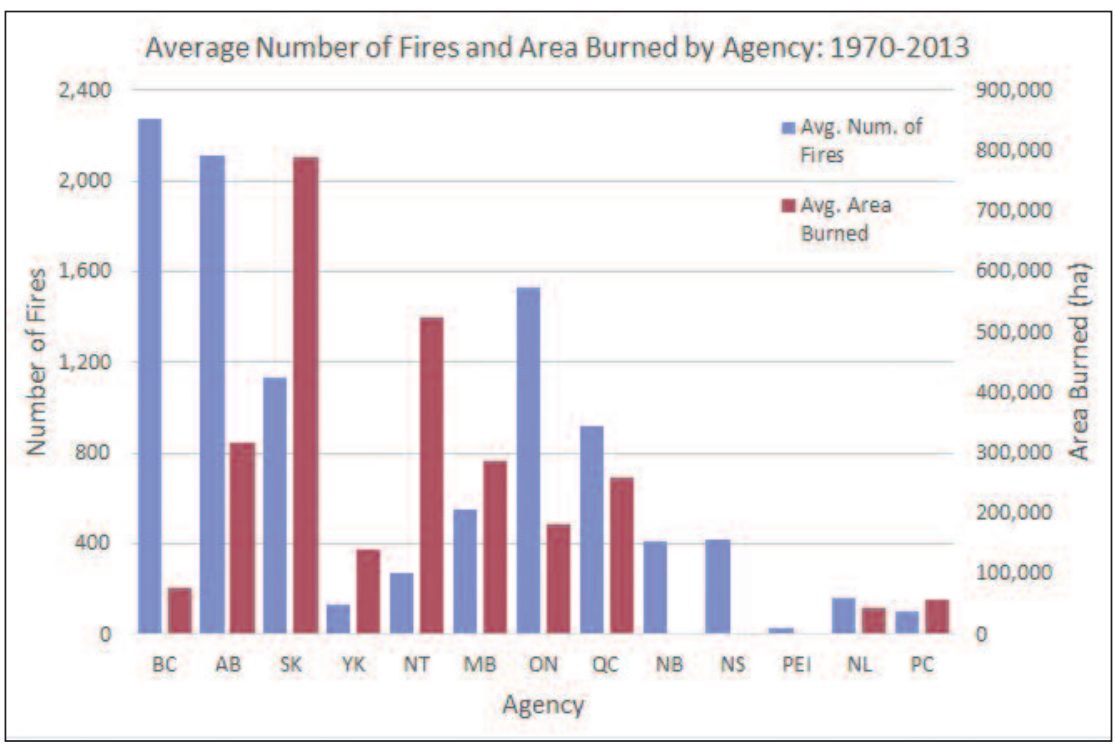

Fig. 1. Average annual number of fires and area burned statistics for Canadian forest fire management agencies for the 1970-2013 period.
The economic foundations of forest and wildland fire management Forest fire managers use the term "fire economics" to describe the economic aspects of their programs and despite the widespread belief that they can easily draw on "emergency fire-fighting" or

\footnotetext{
${ }^{3}$ Codes used to designate each agency are, from west to east: British Columbia (BC), Alberta (AB), Saskatchewan (SK), Yukon Territory (YK), Northwest Territories (NT), Manitoba (MB), Ontario (ON), Quebec (QC), New Brunswick (NB), Nova Scotia (NS), Prince Edward Island (PE), Newfoundland and Labrador (NF), and Parks Canada (PC). Nunavut, which was part of the Northwest Territory until its creation on April 1, 1999, does not have a significant wildland fire management problem or agency.
} 
EFF funds to enhance their capabilities when fire loads escalate, they have long been concerned with carrying out their operations in a cost effective manner. The terms pre-suppression and suppression (or fixed and variable costs) are used to describe the two cost components of a fire management program. The pre-suppression costs include the fixed costs of hiring, training and equipping fire fighters, acquiring aircraft and constructing and maintaining buildings and other supporting infrastructure that are incurred or contracted for prior to the start of the fire season. Suppression costs include the extra costs incurred as the season progresses when fire fighters are called upon to work overtime, additional fire fighters are hired, extra aircraft are hired on short term leases and fire suppression resources are temporarily borrowed from other agencies through the Canadian Interagency Forest Fire Centre (CIFFC) in Winnipeg.

Headley (1916) is often described as having made the earliest documented contributions to the foundations of fire economics based on his suggestions concerning fire suppression efficiency in the "Suppression Financial Policy" section of his fire suppression manual for District 5 (California) of the US Forest Service. The "Least Cost plus Damage" or LCD model, the basic principles of which were articulated by and explored in detail in Sparhawk (1925), are depicted in Fig. 2.

The LCD model is based on the assumption that burned area, the resulting damage and EFF expenditures, are decreasing functions of basic fire management effort expressed in terms of pre-suppression expenditures (p) and it can, in principle, be used to identify an optimal fire management presuppression budget, one that will minimize the total cost of pre-suppression, suppression and fire loss. The downward sloping line indicates that the fire cost, the cost of suppressing fires beyond the base budget (e.g., EFF funds) and the damage incurred, decrease as the pre-suppression budget (the straight line) increases. The optimum pre-suppression budget is the one for which the total cost plus loss is minimized. The LCD model is now sometimes referred to as the "Least Cost plus Net Value Change” model (Donovan and Rideout 2003) in response to growing recognition that fire can and sometimes does have beneficial ecological impacts, but one can treat benefits as negative costs and retain the use of the LCD term.

Canadian fire management agency interest in fire economics grew in the 1960s when Williams (1969) published his "Economics of Forest Fire Control" paper in the Pulp and Paper Magazine of Canada. He described the LCD theory as being "a very difficult theory to apply" and pointed out that "people began to look at the economics of forest fire control and, in doing so, realized what a complex problem they were faced with and how little data they had with which to work." He described Beall's (1949) article "An outline of forest fire protection standards", published in The Forestry Chronicle, as being "the first in-depth study of forest fire control in Canada". He suggested that systems analysis and operational research methods could be used to help resolve strategic fire management program evaluation and budgeting problems but stressed the need to address the difficult problem of assessing the economic impact of fire. In the 1960s and 1970s the Associate Committee on Forest Fire Protection and its successor, the Canadian Committee on Forest Fire Control (subsequently re-named the Canadian Committee on Forest Fire Management) urged the Forest Fire Research Institute of the then Federal Department of Forestry and Rural Development, to devote efforts to fire economics questions (Brady 1979). Despite those initiatives, Canadian fire management agencies and the governments that fund them have grown increasingly concerned about escalating fire management costs in recent years and we believe it is time to re-visit the fire economics problem as it pertains to Canada. Our hope is that publication of the results of our summary of the 1970-2013 fire management expenditure data and making the data widely available will encourage others to initiate more investigations of this important topic.

\section{Methods}

Fire expenditures are compiled annually by Provincial and Territorial forest fire management agencies and by Parks Canada and these data have been summarized nationally and made public in recent decades. Initial summaries were compiled by the Canadian Forest Service (CFS) and published in a series of reports covering 1979-1990 (Ramsey and Higgins 1982, 1985, 1991; Higgins and Ramsey 1992). With the establishment of the National Forestry Database Program (NFDP) under the CCFM in 1990, fire expenditure data was included along with other forest fire statistics, and summarized on the NFDP website for 1970-2000. These data were collected annually from all agencies for the 1970-1978 and 1991-2000 periods and added to the NFDP website along with the 1979-1990 data from the Ramsey/Higgins reports. While other forestry and fire data continued to be collected by the NFDP after 2000, the collection of fire costs proved complicated and was halted at that time. In fact, the 1970-2000 fire

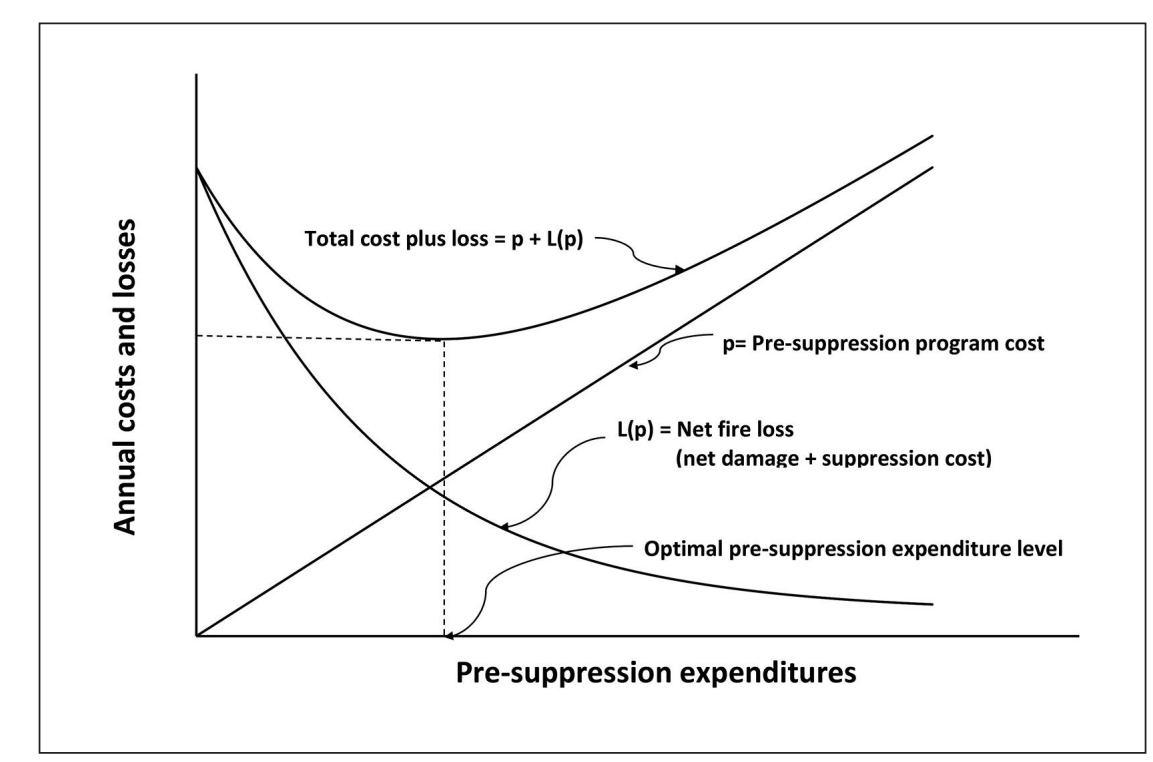

Fig. 2. Least cost plus damage fire economics model. 


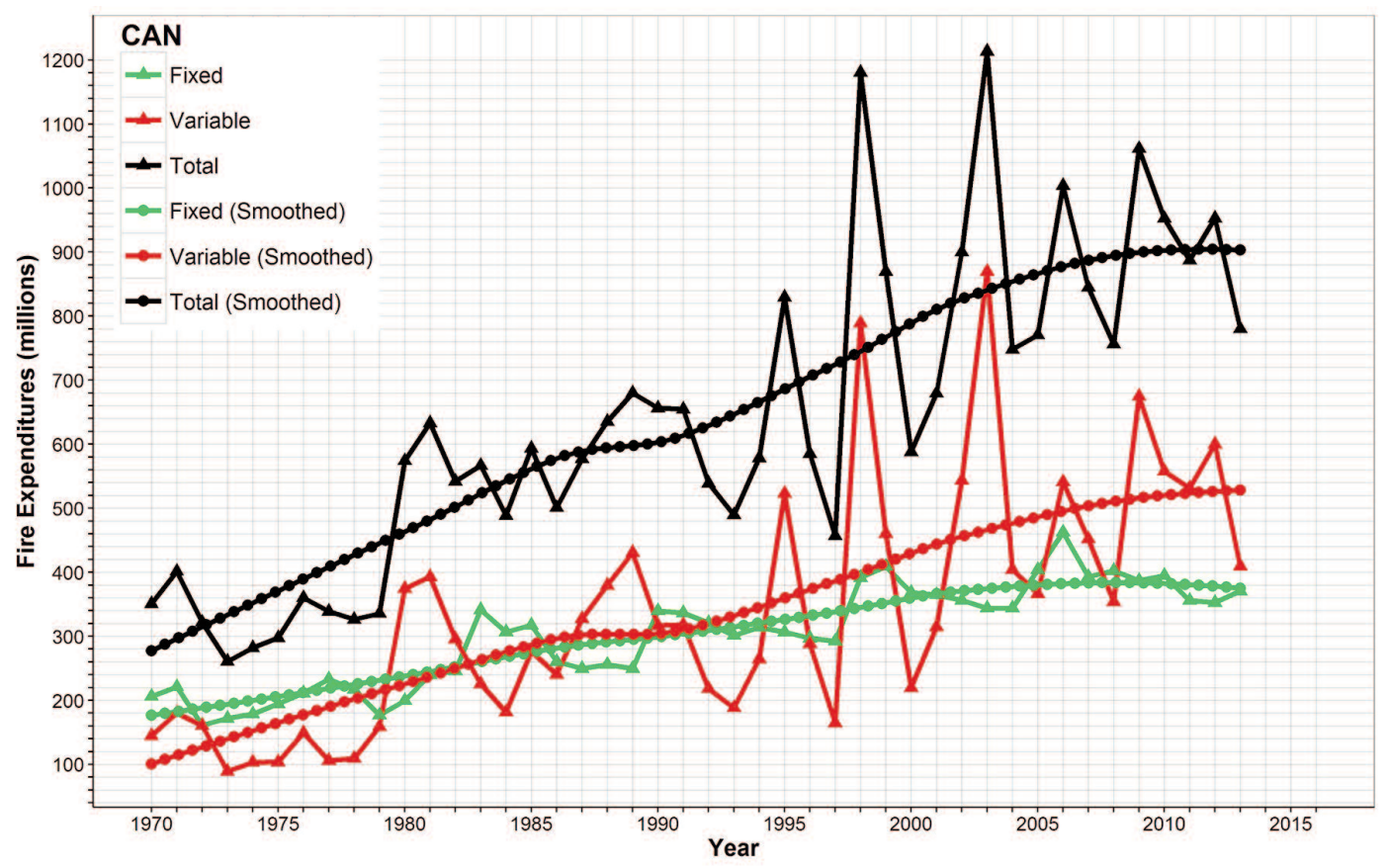

Fig. 3. Forest fire management expenditures in Canada: 1970-2013.

expenditure data was removed from the NFDP website in 2004, and is no longer available there. In order to investigate a growing concern that fire expenditures were rising rapidly post-2000, but were no longer being summarized nationally, all agencies were surveyed by a contractor (B.J. Stocks Wildfire Investigations Ltd.) and provided annual data up to 2009, along with a few corrections (primarily in $\mathrm{ON}$ and $\mathrm{BC}$ ) to the earlier NFDP numbers. The addition of these years resulted in a 40-year dataset (1970-2009) that was recently analyzed as a part of an investigation of fire load in Canada (Stocks 2014). More recently, fire management agency expenditures for 2010-2013 were collected by CIFFC.

Our analysis covers fire expenditures for the 44-year period between 1970 and 2013. Our first step was to normalize the data to make years comparable by converting the expenditures into 2013 \$, using the annual Consumer Price Index (CPI). ${ }^{4}$ We then plotted the fixed, variable and total costs for all of Canada and each Canadian fire management agency. The year-to-year variation in a fire management agency's expenditures makes it very difficult to detect trends in many of the graphs that resulted. We therefore used the ggplot2 R function (Wickham, 2009) to plot annual fire management expenditures and R's loess function (R Core Team, 2015) to produce the corresponding loess non-parametric regression trend lines in for Canada and each agency.

\footnotetext{
${ }^{4}$ We used the CPI but since forest fire management agencies are not "consumers", other economic indicators may be more appropriate. Personal communication, S. Andersen, Ontario Ministry of Natural Resources, January 19, 2015.
}

It is important to note that since the fire management costs compiled, presented and analyzed in this report are those reported by Canadian fire management agencies over more than four decades, thorough retroactive quality control checking on these data is not possible. We have done our best to ensure the validity of the data and our assumption is that it is adequate for our preliminary analysis of national fire expenditure trends. Our hope is that others will start with this data and initiate detailed economic studies of Canadian fire management agencies and that will bring any errors or omission to our attention so we can correct any errors they detect and make the corrected data publicly available.

\section{Results}

As was noted earlier, most Canadian forest fire management agencies classify their annual expenditures as being either fixed or variable costs. Although the terms used may vary between agencies, fixed expenditures are those associated with maintaining the fire management program (e.g., infrastructure, permanent staff salaries) and tend to remain relatively constant over time except when new polices are implemented or fire programs are bolstered or cut back in response to recent fire activity. Variable expenditures include the cost of additional non-permanent resources such as extra fire fighters provided by contractors or borrowed from other agencies, and helicopters and fixed-wing aircraft that are chartered for relatively short periods of time to deal with heavy fire loads, and can vary significantly from year to year. The terms pre-suppression and suppression are also commonly used to describe fixed and variable expenditures respectively. 
National total fixed, variable and total annual wildland fire costs for 1970-2013 and their corresponding loess smoothed trend lines are presented in Fig. 3. As expected, variable costs fluctuate much more on an inter-annual basis than fixed costs. Overall costs have been rising steadily since 1970, but have increased significantly since the mid-1990s. In addition, variability between years also increased markedly during this period. Overall fire management expenditures (in 2013 dollars) have risen from approximately $\$ 290$ million (M) in the early 1970s to more than $\$ 900 \mathrm{M}$ in 2013.

Fixed, variable and total fire expenditures for the 13 individual Canadian fire management agencies over 1970-2013 are shown in Fig. 4. Fixed expenditures rise more slowly and exhibit much less inter-annual variability than variable expenditures, and this fact is common to all agencies. Since there are large differences in expenditures between agencies, it is also important to remember that the size of the fire management zone varies by agency. Although we are interested in and explore how trends vary from agency to agency, our data does not permit, nor was it our intention, to compare, for example, variation in fire activity (e.g., number of fires that occur and area burned) and fire management expenditures between agencies.

We now refer to the larger scale higher resolution versions of the thirteen graphs in Fig. 4 along with their loess trend lines that are available as S.Fig. 5 through to S.Fig. 17 in the on-line version of this paper and briefly summarize what transpired within each agency during our study period.

\section{British Columbia}

British Columbia is home to some of Canada's most active fire regimes, particularly in its relatively dry southern intermountain interior and large portions of the interior that experienced a sustained outbreak of mountain pine beetle which began in the 1980s, causing widespread mortality in lodgepole pine stands.

BC's fixed cost loess trend line in S.Fig. 5 gradually increased from $\$ 30 \mathrm{M}$ in 1970 to approximately $\$ 60 \mathrm{M}$ in 1990 before gradually decreasing back to $\$ 30 \mathrm{M}$ in 2013 . The variable cost trend line increased at a slightly higher rate but peaked at about $\$ 100 \mathrm{M}$ in 1986 after which it declined slightly to approximately $\$ 85 \mathrm{M}$ in 1995 and then began to increase, slowly at first, then more rapidly to $\$ 170 \mathrm{M}$ in 2013. The total cost trend line exhibited similar behaviour, culminating at $\$ 160 \mathrm{M}$ in 1987 , declining to $\$ 140 \mathrm{M}$ in 1996 , and then increasing to approximately $\$ 205 \mathrm{M}$ in 2011 after which it exhibited a slight decrease to about $\$ 200 \mathrm{M}$ in 2013. Total $\operatorname{costs}^{5}$ were more variable during 1985-2000 than during 1970-1984 but became much more variable during 2001-2013, due to increased fluctuations in variable costs. BC's most costly year during our study period was 2003 when the Kelowna, McClure and many other, large and destructive fires occurred.

\footnotetext{
${ }^{5}$ Note that since the fixed, variable and total cost trend lines are smoothed curves, the smoothed total cost will not necessarily equal the sum of the smoothed fixed and variable cost curves.
}

\section{Alberta}

With the notable exceptions of the years 1979, 1981 and 1982, fire management expenditures in the province of Alberta shown in S.Fig. 6 were relatively stable during 1970-1990. The fixed cost trend line increased gradually from about $\$ 15 \mathrm{M}$ in 1970 to $\$ 40 \mathrm{M}$ in 1990, after which it increased relatively quickly at first, then more slowly to level off at about $\$ 120 \mathrm{M}$ in 2008 before gradually decreasing to about $\$ 105 \mathrm{M}$ in 2013. Variable costs increased to $\$ 50 \mathrm{M}$ in 1986 after which they declined to $\$ 30 \mathrm{M}$ in 1990 and then increased almost linearly to $\$ 180 \mathrm{M}$ in 2013 . The total cost exhibited a similar trend, peaking at $\$ 90 \mathrm{M}$ in 1986 , declining to $\$ 70 \mathrm{M}$ in 1990 and then increasing steadily to $\$ 290 \mathrm{M}$ in 2013 . Underlying those trend lines is a very sharp increase in fixed costs from $\$ 40 \mathrm{M}$ in 1991 to $\$ 120 \mathrm{M}$ in 2007 . With the exception of 1980 , 1981 and 1982, variable costs were relatively stable during the 1970 through 1997 period, and much like British Columbia, became much more variable during the 1998 through 2013 period. Given the proximity of Alberta to British Columbia and the Pacific Ocean and the fact that sea surface temperatures and associated upper level atmospheric circulation patterns are believed to have a significant impact on fire activity in western Canada, (Skinner et al. 2006), it's not surprising that fire management expenditures have exhibited similar patterns in variation in Alberta and British Columbia in recent years.

\section{Saskatchewan}

Saskatchewan's smoothed fixed costs were virtually zero in the early 1970s (the actual fixed cost in 1970 was $\$ 1.4 \mathrm{M}$, increased rapidly after 1976 , gradually levelled out at $\$ 30 \mathrm{M}$ during the 1992-1996 period.) Fixed costs then increased to $\$ 45 \mathrm{M}$ in 2007 and declined to $\$ 40 \mathrm{M}$ in 2013. Note that actual fixed costs increased from $\$ 38 \mathrm{M}$ in 2004 to $\$ 83 \mathrm{M}$ in 2005 , then declined rapidly to $\$ 45 \mathrm{M}$ in 2007 and $\$ 33 \mathrm{M}$ in 2010. Variable costs increased steadily from almost zero in 1970 (the actual that year was \$9.4 M) until they levelled out at $\$ 50 \mathrm{M}$ in 1996 after which they declined quite quickly to $\$ 10 \mathrm{M}$ in 2013. Total costs followed a similar trend, increasing from almost nothing in 1970 to gradually leveling off at $\$ 85 \mathrm{M}$ in 2001 and then declining rapidly to $\$ 50 \mathrm{M}$ in 2013. Total costs grew more variable beginning in 1979, peaked near 1995 then gradually became less variable in subsequent years.

\section{Manitoba}

Manitoba's smoothed fixed costs began at about \$5 M in 1970 and gradually increased to about $\$ 18 \mathrm{M}$ in 2000 from which they gradually decreased to about $\$ 16 \mathrm{M}$ in 2013. Its suppression costs increased linearly from close to zero in 1970 to about $\$ 25 \mathrm{M}$ in 1985 , then linearly at a decreased rate to $\$ 35$ $\mathrm{M}$ in 2013. Its total costs exhibited a similar trend, increasing linearly from about $\$ 2 \mathrm{M}$ in 1970 to about $\$ 37 \mathrm{M}$ in 1985 , then at a slower rate to about \$52 M in 2013.

\section{Yukon Territory}

Fire management expenditure patterns in the Yukon Territory differ significantly from the patterns observed in the Northwest Territories and the ten provinces. Fixed costs began at approximately $\$ 5 \mathrm{M}$ in 1970 and increased until they leveled off at approximately $\$ 9 \mathrm{M}$ in 1987 after which they 

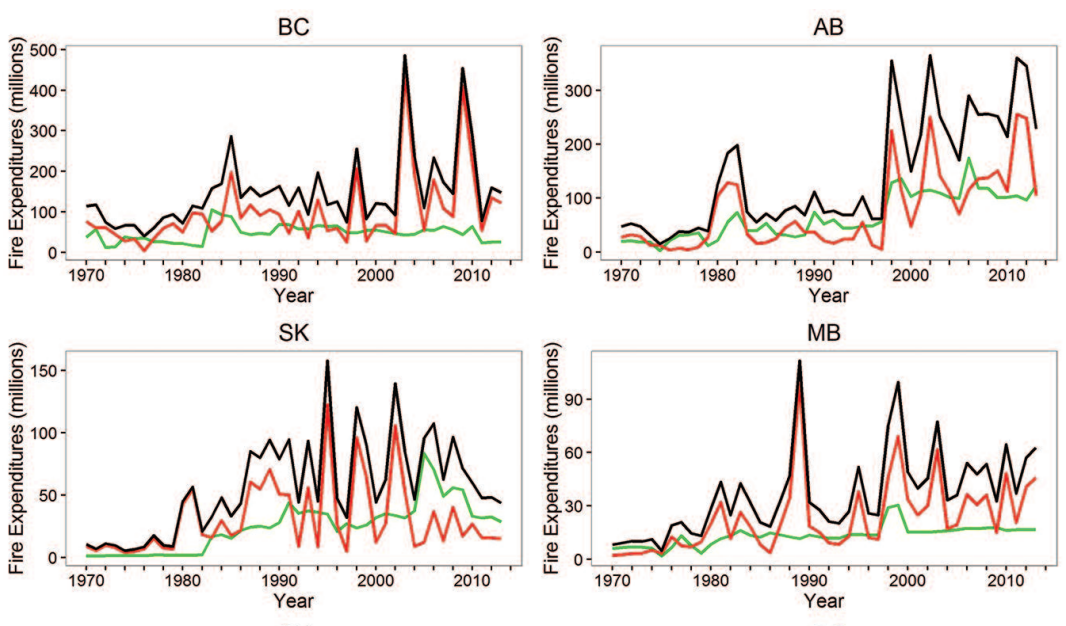

ON
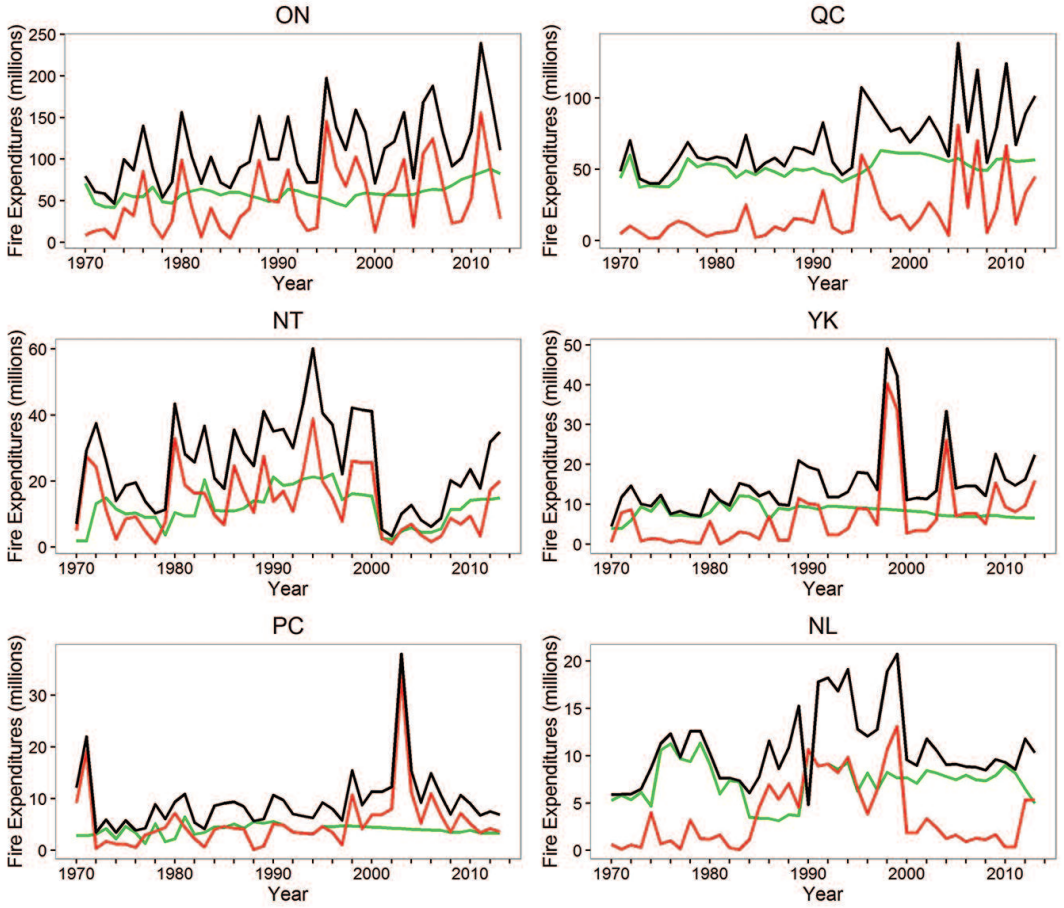

NB
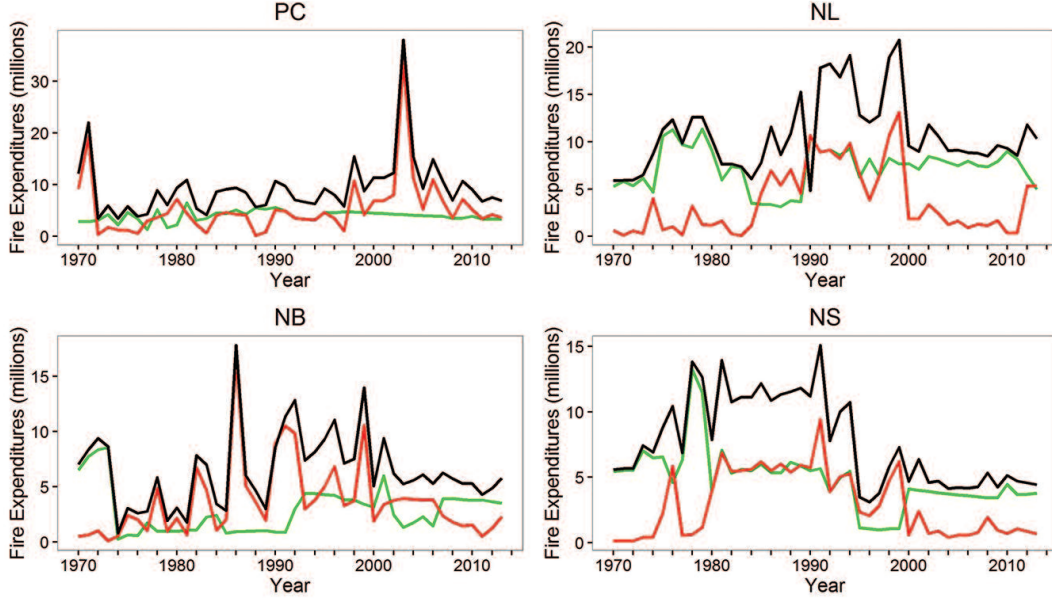

NS

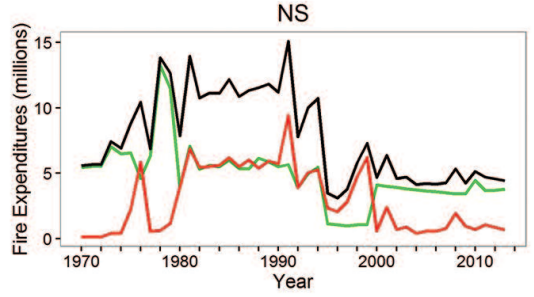

PE

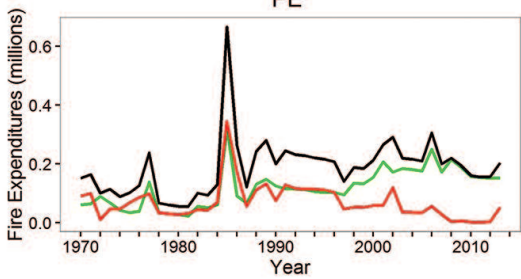

declined at a linear rate to about $\$ 6 \mathrm{M}$ in 2013. Suppression costs began at close to $\$ 5 \mathrm{M}$ in 1970 , decreased until they levelled off at about $\$ 2 \mathrm{M}$ in 1980 but then increased, faster than they had decreased, to about \$12 M in 1999 from which they declined to about $\$ 10 \mathrm{M}$ in 2013. Total costs exhibited a similar trend, beginning at about $\$ 10 \mathrm{M}$ in 1970 , increasing to $\$ 21 \mathrm{M}$ in 1998 , then decreasing to $\$ 16 \mathrm{M}$ in 2013. With the exception of very significant peaks in 1998, 1999 and 2004, the variability in total cost did not change significantly during our study period.

\section{Northwest Territories}

The Northwest Territories' fixed costs increased linearly from $\$ 7 \mathrm{M}$ in 1970 to $\$ 13 \mathrm{M}$ in 1985 after which they increased more rapidly to level off at about $\$ 18 \mathrm{M}$ in 1991, then decreased to $\$ 10 \mathrm{M}$ in 2006 before increasing to $\$ 14 \mathrm{M}$ in 2013. The suppression cost trend was somewhat similar to that of the Yukon, beginning at $\$ 14 \mathrm{M}$ in 1970, dipping to about $\$ 12 \mathrm{M}$ in 1976 , then increasing until it leveled off at $\$ 20 \mathrm{M}$ in 1991 from which it gradually, then more rapidly, declined to about $\$ 10$ $M$ in 2013. Its total cost began at $\$ 21$ $M$ in 1970, then began to increase, initially at an increasing rate until it levelled off at \$38 M in 1992, from which it declined, slowly at first and then more rapidly, to eventually level off at $\$ 19 \mathrm{M}$ in 2008 and then climbed rapidly to \$24 M in 2013.

\section{Ontario}

Ontario's fixed costs were about $\$ 50 \mathrm{M}$ in 1970 and very gradually increased to $\$ 60 \mathrm{M}$ in 2003 after which they increased linearly at a rate of approximately $\$ 3 \mathrm{M}$ per year to $\$ 90 \mathrm{M}$ in 2013. Variable costs increased linearly from $\$ 20 \mathrm{M}$ in 1970 to $\$ 40 \mathrm{M}$ in 1987 , after which they increased linearly at a faster rate to $\$ 70 \mathrm{M}$ in 1997 where they remained until 2013. Total costs increased linearly from $\$ 70 \mathrm{M}$ in 1970 to $\$ 150 \mathrm{M}$ in 2013 . Total costs remained quite variable throughout our study period but perhaps more so beginning in 1994.

Fig. 4. Annual fire management expenditures for all Canadian forest fire management agencies for the 1970-2013 period. 


\section{Quebec}

Quebec's fixed costs were about \$45 M in 1970 and remained close to that value until 1991 when they began slowly increasing from $\$ 48 \mathrm{M}$ to peak near $\$ 58 \mathrm{M}$ then decline to about $\$ 55$ $M$ in 2013. Their suppression costs began at about $\$ 8 \mathrm{M}$ in 1970 from which they gradually increased to approximately $\$ 17 \mathrm{M}$ in 1990 and then increased linearly to \$40 M in 2013. Their total costs began at $\$ 50 \mathrm{M}$ in 1970 , increased linearly to $\$ 80 \mathrm{M}$ in 1998, then began increasing and gradually levelled off at $\$ 90 \mathrm{M}$ in 2013. Total costs exhibited moderate variability during the 1970-1993 period but became more variable during the 1994-2013 period.

\section{New Brunswick}

New Brunswick's fixed costs were \$7.7 M in 1970 but declined rapidly to level off at $\$ 1 \mathrm{M}$ in 1982 after which they gradually increased to $\$ 3.5 \mathrm{M}$ in 1998 and remained stable at this level until 2013. The smoothed suppression costs increased at a rapid linear rate from almost zero in 1979 (the actual 1970 suppression cost was $\$ 0.5 \mathrm{M}$ ) to level off at $\$ 6.5 \mathrm{M}$ in 1991 , then deceased at a steep linear rate to $\$ 1 \mathrm{M}$ in 2013. The total cost decreased from $\$ 7.5 \mathrm{M}$ in 1970 to level off at $\$ 4.8 \mathrm{M}$ in 1980, increased to and levelled off at about $\$ 9 \mathrm{M}$ in 1993 and decreased at a linear rate to $\$ 4.2 \mathrm{M}$ in 2013 .

\section{Nova Scotia}

Nova Scotia's fixed costs began at \$5.5 M in 1970, then increased to level off at \$7 M in 1979 from which it decreased to $\$ 3 \mathrm{M}$ in 1998 then increased to $\$ 4.5 \mathrm{M}$ in 2013. Its smoothed suppression cost trend line started at less than $\$ 0$. M in 1970 (its actual 2013 suppression cost was $\$ 0.13 \mathrm{M}$ ), peaked at $\$ 6 \mathrm{M}$ in 1987 then decreased to $\$ 0.8 \mathrm{M}$ in 2013. Its total cost started at $\$ 4.5 \mathrm{M}$ in 1970 , increased rapidly to $\$ 12$ $\mathrm{M}$ in 1985 , decreased to about $\$ 4.2 \mathrm{M}$ in 2006 , then gradually increased to about \$ $4.5 \mathrm{M}$ in 2013.

\section{Prince Edward Island}

Since Prince Edward Island is Canada's smallest province and much of its land is devoted to agriculture, it is not surprising that it has the smallest fire management program. Its fixed costs increased linearly from about $\$ 0.05 \mathrm{M}$ in 1970 to $\$ 0.17$ $\mathrm{M}$ in 2013. Its variable cost increased linearly from about $\$ 0.06 \mathrm{M}$ in 1970 to about $\$ 0.12$ in 1990 , then decreased linearly to about $\$ 0.01 \mathrm{M}$ in 2013. Its total cost increased from $\$ 0.12 \mathrm{M}$ in 1970 to $\$ 0.25 \mathrm{M}$ in 1991 , then decreased to about $\$ 0.18 \mathrm{M}$ in 2013 .

\section{Newfoundland and Labrador}

Newfoundland and Labrador's fixed costs started at \$7 M in 1970, increased slightly during the next five years, then decreased to $\$ 6 \mathrm{M}$ in 1986 from which they increased to \$8 M in 1997 where they remained for several years, then decreased to $\$ 6.5$ in 2013. Their variable costs increased rapidly from about $\$ 0.8 \mathrm{M}$ in 1970 to $\$ 8 \mathrm{M}$ in 1993 , then declined at almost the same rate, to $\$ 2 \mathrm{M}$ in 2013. Their total costs started at about $\$ 7.5 \mathrm{M}$ in 1970 , increased linearly to $\$ 10$ in 1986, then increased more rapidly to eventually level off at \$15 M in 1996 from which they declined quickly at a linear rate to $\$ 8.5$ in 2013.

\section{Parks Canada}

Parks Canada's fixed costs remained relatively stable over our entire study period, beginning at about \$3 M in 1970, increasing gradually to $\$ 4.5 \mathrm{M}$ in 1991 then decreasing gradually to about $\$ 3.5 \mathrm{M}$ in 2013 . Variable costs declined gradually from $\$ 8 \mathrm{M}$ in 1970 to $\$ 3 \mathrm{M}$ in 1981 where they remained relatively stable until 1991, then increased to \$9 M in 2003 after which they declined to $\$ 3.5$ in 2013 . The total cost trend line exhibited similar behaviour, beginning at $\$ 10.5 \mathrm{M}$ in 1970 , reaching $\$ 7.5$ in 1991, increasing to \$13 M in 2003 then decreasing to about \$7 M in 2013.

\section{Discussion}

The LCD model is a strategic planning model that can, in principle, be used to help fire management agencies evaluate alternative fire management policies or strategies and identify an optimal pre-suppression (fixed) expenditure level for each strategy they wish to consider. Suppose for example, a fire management agency was responsible for fire management on a tract of land that was used solely for timber production and its strategy was to minimize the average cost plus loss with pre-suppression and suppression (variable) costs classed as costs and the reduction in the value of the timber resource the loss. One could develop a model that relates the suppression cost and timber loss to the pre-suppression expenditure and find the pre-suppression expenditure that minimizes the sum of those three terms, the "optimal" pre-suppression budget. Unfortunately, the real problem is far more complicated than that.

When the pre-suppression budget level is established at the beginning of each year, fire mangers do not know what kind of weather will materialize that year and since weather, subsequent fire occurrence and fire behaviour vary so much from year to year, they must resolve a very complex problem of decision-making under uncertainty. Consider the very simple timber production problem outlined in the preceding paragraph. The impact of fire on timber supply has been an active subject of research beginning with Van Wagner (1983) and Gassmann's (1989) seminal contributions and more recent contributions by Boychuk and Martell (1996) and many others. However, no one has, to our knowledge, generated probabilistic fire season weather scenarios and used them to determine an optimal pre-suppression budget for the simple problem in which timber values alone are the fire loss being mitigated by a fire management program.

The real world is, as our readers are well aware, even more complicated. Canadian forest fire management programs were established and have been maintained to satisfy public safety objectives, mitigate the impact of fire on property and forest resources, and more recently, to help deliver the ecosystem services that flow from fires that benefit natural ecosystem processes. Furthermore, when Canadian fire managers decide upon their pre-suppression budget levels, they must consider the fact that the resources they acquire will be shared between regions within their provinces and territories, with other provinces, and even other countries. In addition, changes in attitudes concerning the value of timber and other forest resources, land use patterns and their impact on fire ignition processes and forest fuel complexes, government fiscal capac- 
ities and priorities and climate change may also have impacted pre-suppression budgets. Addressing any one or more such factors will call for a whole new level of complexity that must be considered if LCD concepts to be brought to bear upon strategic fire management planning. Given the inability and/or unwillingness of others to provide fire managers with sound estimates of the economic impact of their strategies, fire managers have and will continue to have to use surrogate value measures (e.g., area burned) to assess their impact.

Canadian fire management agencies do document some fire losses but since the methods used to do so have varied over time and from agency to agency, it would be difficult to estimate even the property losses incurred and include them in LCD-type analyses to determine the extent to which the pre-suppression or fixed costs described in this report have been or are optimal. All is not lost however. Canadian forest fire management agencies provide a public service and they have an implicit social contract with their clients, the governments that fund their operations and the people those governments represent. They have not nor can they be expected to identify an optimal fire management strategy and corresponding pre-suppression budget that accounts for all of the many costs and benefits of a fire management program, and we don't expect that problem to be resolved anytime soon. Their current objective should perhaps be characterized as minimizing the cost of a fire management program that produces what their governments expect of them in the form of, for example, public safety expressed in terms of lives lost and communities threatened and evacuated homes, cabins and other structures and infrastructure destroyed, area burned, industrial timber destroyed, and beneficial ecosystem impacts.

Some Canadian fire agencies were established in the early decades of the twentieth century and they grew and shrunk in response to the preferences of their political masters. It's not unreasonable to assume that, at the conclusion of a fire season during which catastrophic losses were incurred, governments reviewed what had happened and determined the extent to which policies and strategies should change and pre-suppression budgets should be revised in concert with such changes. It's also reasonable to assume that pre-suppression budgets were revised downward following several consecutive years during which little area burned and few losses were incurred. We are not privy to such deliberations and the investigation of such phenomena is well beyond the scope of our study, but we encourage economists, political scientists and other social scientists to study what has happened and investigate what appears to have motivated changes in policies and pre-suppression budgets in individual agencies over the years.

In a simple world in which land-use activity, forest resource values, climate and fiscal factors that limit the extent to which governments can fund fire management programs, given the many competing calls on their resources did not vary over time, one could hypothesize that if the governments that fund fire management programs behaved as we have outlined above, the pre-suppression budgets of each of the agencies should have begun at the levels indicated in 1970 and ebbed and flowed and eventually reached what might be described as a social equilibrium wherein they were minimizing the cost of achieving what the governments that funded them expected of them. To what extent if any, are the pre-suppression expenditures consistent with such an assumption?

The trend lines of pre-suppression expenditures of several of the larger Canadian forest fire management agencies exhibit behaviour that is consistent with a need to improve their effectiveness during the period beginning in 1970 and ending in roughly 1990 . BC, AB, SK, MB, QC, YK, NT all gradually increased their pre-suppression levels over the 1970 to roughly 1990 period, which is consistent with a need to improve their effectiveness, as did two of the smaller agencies (PE and PC).

$\mathrm{BC}$ and the YK then began to gradually decrease their presuppression budgets to 2013 levels while MB continued to grow until about 2000 then gradually levelled off close to 2013 levels. SK remained stable for several years then began to increase to its 2013 level. QC began to increase until 2003 then began to level off while ON remained relatively stable until 2003 then began to increase its pre-suppression budget.

These trends are consistent with an assumption that most of the larger Canadian fire management agencies began growing in 1970 in response to a need to better achieve what was expected of them (or to meet new expectations) up until 1990, and that in some cases, they were then expected to either do more, respond to reduced expectations, or achieve what was expected of them with less resources. It would be interesting to explore in detail, what factors may or may not have contributed to the changes in pre-suppression expenditures, an important topic that is well beyond the scope of our study.

\section{Conclusions}

Fire mangers are well aware of the need to estimate the economic impact of their programs but lack the expertise and resources required to do so, and quite rightly expect economists and social scientists to undertake such research, in collaboration with fire management agencies. The Canadian Committee on Forest Fire Management identified fire economics as a very high priority research topic in the 1970s and that resulted in the CFS initiating some research on that topic at that time. Unfortunately, little or nothing significant has happened since then. Our results suggest there is an urgent need to study the economics of fire management in Canada.

The results of our review of Canadian forest and wildland fire management expenditures indicate that, from a national perspective, both fixed (pre-suppression) and variable (suppression) expenditures have been increasing since 1970 and have become more variable, particularly since the mid-1990s. We feel there is no reason to believe, given the growth of the wildland urban interface, changes in land uses patterns, the growing impact of fire on public health and safety, climate change, and many other factors that those trends will not continue for some time. We anticipate growing public and political acceptance that fire is a natural ecosystem process that cannot and should not be excluded from our forested landscapes, and fiscal constraints will accelerate the shift from fire exclusion to the policies of fire impact management that has grown in recent years. Fire managers that are experienced at managing initial attack operations and containing large destructive fires that escape initial attack will be given the additional responsibility of deciding how best to manage 
every fire that is reported, and deciding which of them should be aggressively initial attacked and which should receive a modified response and monitored until they are extinguished by nature or until they pose a serious threat to public safety and forest resources and have to be extinguished.

Increased fire activity on the landscape will accelerate the need to proactively protect communities, and further promote the use of prescribed fire to achieve both fuel management and ecological restoration objectives. We expect these trends and demands will result in a continued increase in fire management expenditures, at least in the short run. This could be followed by a gradual levelling off and then a decrease to a new, possibly less costly equilibrium, where people in forest communities are threatened by smoke and fire, and the residents of much larger distant cities are impacted by wildfire smoke on a more frequent basis. Identifying an appropriate equilibrium and the means to achieve it will pose very significant challenges to fire managers, the governments that support them and, of course, the citizens that will have to live with both the costs and benefits of the difficult choices ahead.

\section{Acknowledgements}

The authors gratefully acknowledge the financial support of the Wildland Fire Management Working Group (WFMWG) of the Canadian Council of Forest Ministers (CCFM) and the Canadian Forest Service (CFS), in the collection of fire expenditure data from Canadian fire management agencies. The Canadian Interagency Forest Fire Centre (CIFFC) also kindly provided data for the 2010-2013 period. David Martell's contribution was supported by a Natural Sciences and Engineering Research Council of Canada (NSERC) Discovery grant (RGPIN-2015-04936). Finally, we thank L. Zhang and R. Santiago for their assistance in preparing our graphs. We thank the associate editor and reviewers for their helpful comments and suggestions on an earlier version of this manuscript.

The dataset that was used to produce the results presented in this paper is publicly available on the University of Toronto Libraries' TSpace research repository at http://hdl.handle. net/1807/73430.

\section{References}

Beall, H.W. 1949. An outline of forest fire protection standards. Forest. Chron. 25(2): 82-106.

Boychuk, D. and D.L. Martell. 1996. A multistage stochastic programming model for sustainable forest-level timber supply under risk of fire. For. Sci. 42(1): 10-26.

Brady, R.P.1979. Forest fire value appraisal. Proceedings of the International Fire Management Workshop. Northern Forest Research Centre, Canadian Forestry Service, Edmonton, Alberta. pp. 17-22, Information Report NOR-X-215
CCFM (Canadian Council of Forest Ministers). 2006. Canadian wildland fire strategy: A vision for an innovative and integrated approach to managing the risks. ISBN 0-662-42194-9

Donovan, G.H. and D.B. Rideout. 2003. A reformulation of the Cost plus Net Value Change (C plus NVC) model of wildfire economics. For. Sci. 49(2): 318-323

Gassmann, H.I.1989. Optimal harvest of a forest in the presence of uncertainty. Can. J. For. Res. 19: 1267-1274

Headley, R.1916. Fire Suppression, District 5. United States Forest Service. 57 p.

Higgins, D.G. and G.S. Ramsey.1992. Canadian forest fire statistics 1988-1990. Forestry Canada, Petawawa National Forestry Institute, Chalk River, Ontario. Information Report PI-X-107. 76 p. http://cfs.nrcan.gc.ca/pubwarehouse/pdfs/10684.pdf

Pyne, S.J. 2007. Awful Splendour: A fire history of Canada. University of British Columbia Press, Vancouver, BC. 549 p.

Ramsey, G.S. and D.G. Higgins. 1982. Canadian forest fire statistics: 1980. Environment Canada, Canadian Forestry Service, Petawawa National Forestry Institute, Chalk River, Ontario. Information Report PI-X-17. 38 p. http://cfs.nrcan.gc.ca/publications?id=12046 Ramsey, G.S. and D.G. Higgins.1985. Canadian forest fire statistics 1981, 1982, 1983. Canadian Forestry Service, Petawawa National Forestry Institute, Chalk River, Ontario. Information Report PI-X49. 148 p. http://cfs.nrcan.gc.ca/publications?id=24169

Ramsey, G.S. and D.G. Higgins.1991. Canadian forest fire statistics 1984-1987. Forestry Canada, Petawawa National Forestry Institute, Chalk River, Ontario. Information Report PI-X-74. 163 p. http://cfs.nrcan.gc.ca/publications?id=10655

R Core Team. 2015. R: A language and environment for statistical computing. R Foundation for Statistical Computing, Vienna, Austria. URL https://www.R-project.org/.

Skinner, W.R, A. Habbar, M.D. Flannigan and K. Logan. 2006. Large forest fires in Canada and the relationship to global sea surface temperatures. J. Geophys. Res. 111: D14106, doi:10.1029/2005 JD006738.

Sparhawk, W.N. 1925. The use of liability rating in planning forest fire protection. J. Agr. Res. 30(8): 693-762.

Stocks, B.J. 2014. Evaluating past, current and future wildland fire load trends in Canada. Report to the Wildland Fire Management Working Group, Canadian Council of Forest Ministers. B.J. Stocks Wildfire Investigations Ltd.

Van Wagner, C.E. 1983. Simulating the effect of forest fire on long term annual timber supply. Can. J. For. Res. 13: 451-457.

Wickham, H. 2009. ggplot2: Elegant graphics for data analysis. Springer-Verlag New York.

Williams, D.E. 1969. Economics of forest fire control. Pulp and Paper Magazine of Canada 70: 97-98 
Supplementary figures to be published on-line for

The Forestry Chronicle article entitled

Forest Fire Management Expenditures in Canada: 1970-2013

B.J. Stocks and David L. Martell

2016 Vol. 92 No. 3

August 19, 2016 


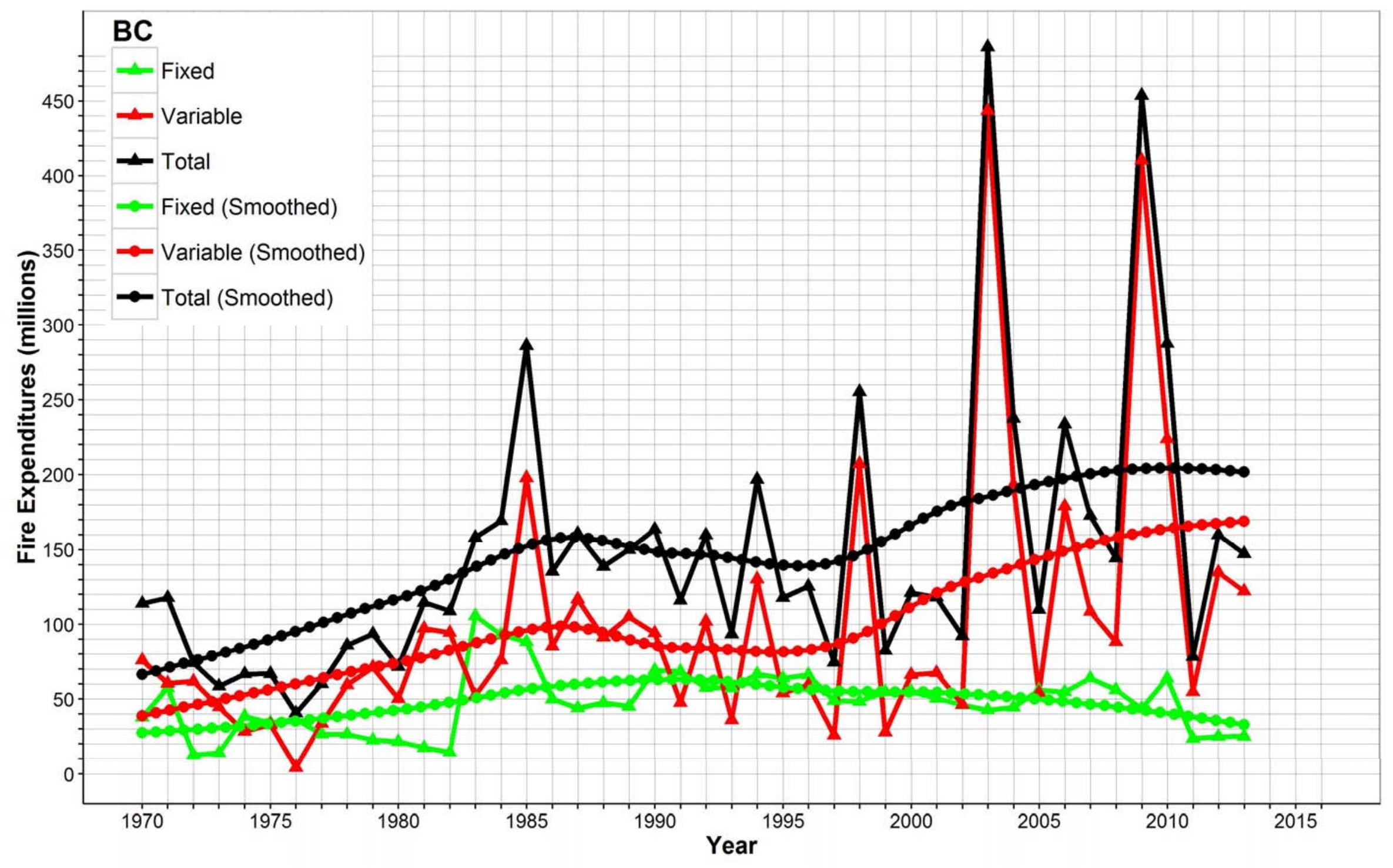

S.Figure 5. Fire management expenditures in the province of British Columbia: $1970-2013$ 


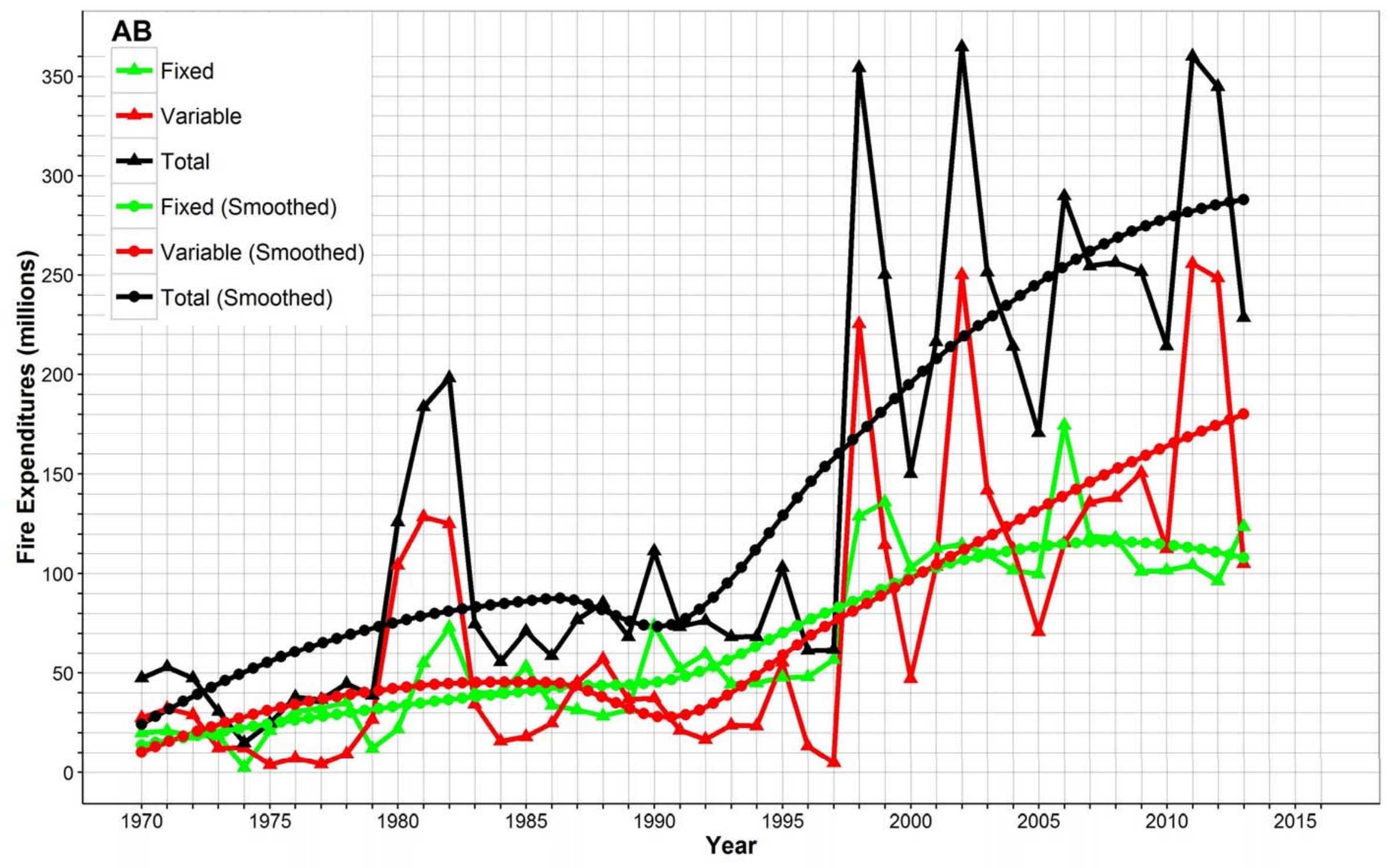

S.Figure 6. Fire management expenditures in the province of Alberta: 1970 - 2013 


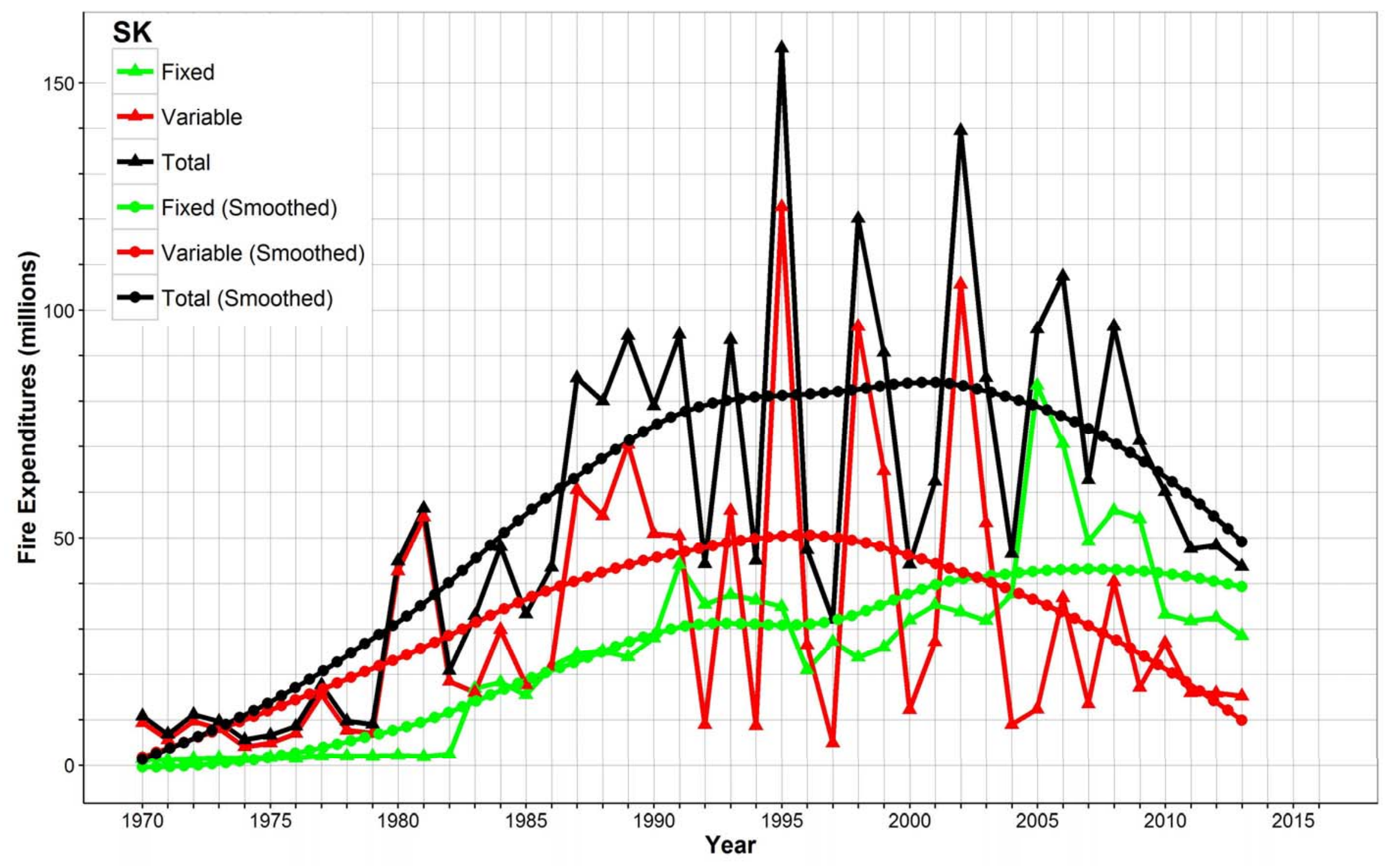

S.Figure 7. Fire management expenditures in the province of Saskatchewan: 1970-2013 


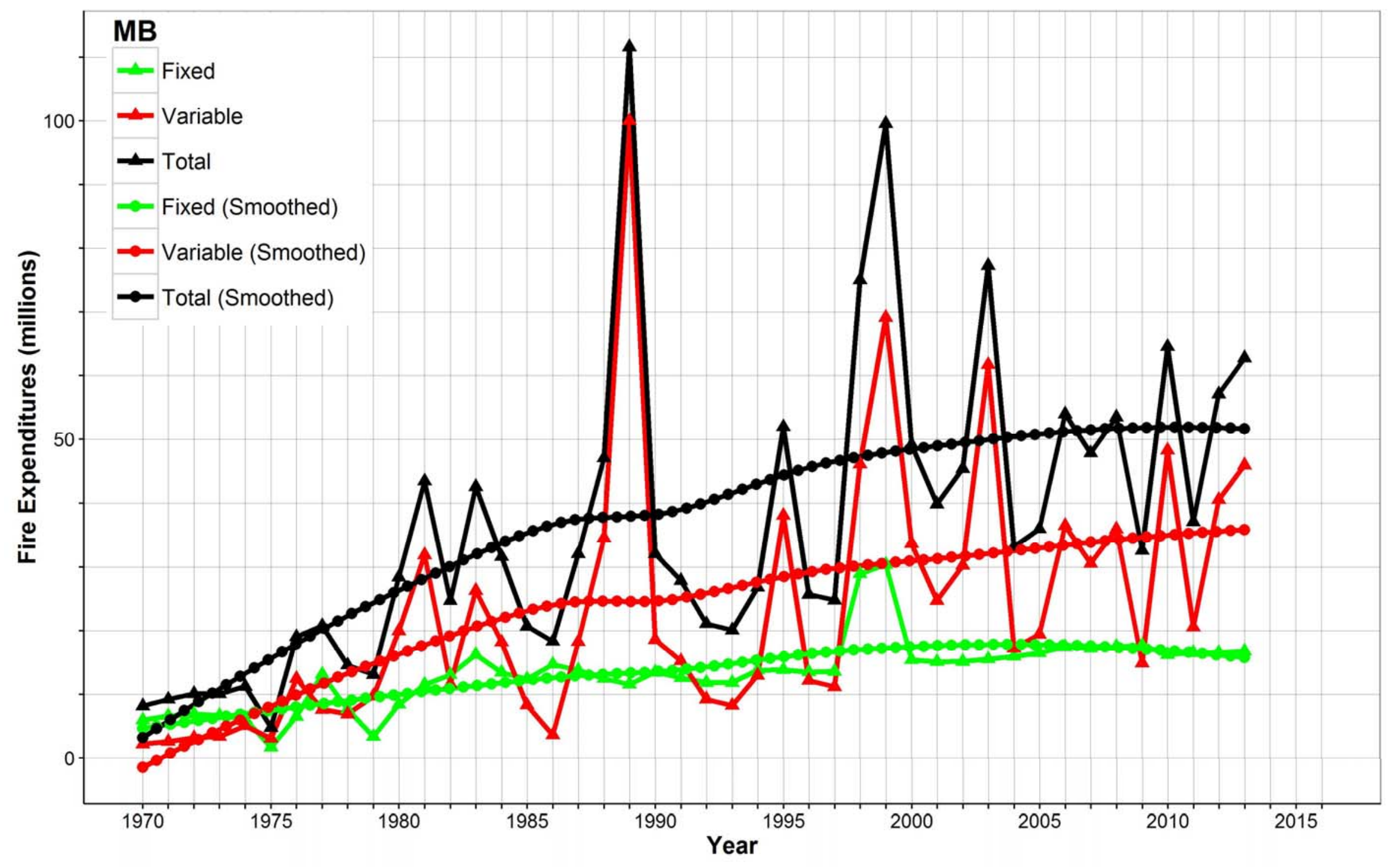

S.Figure 8. Fire management expenditures in the province of Manitoba: $1970-2013$ 


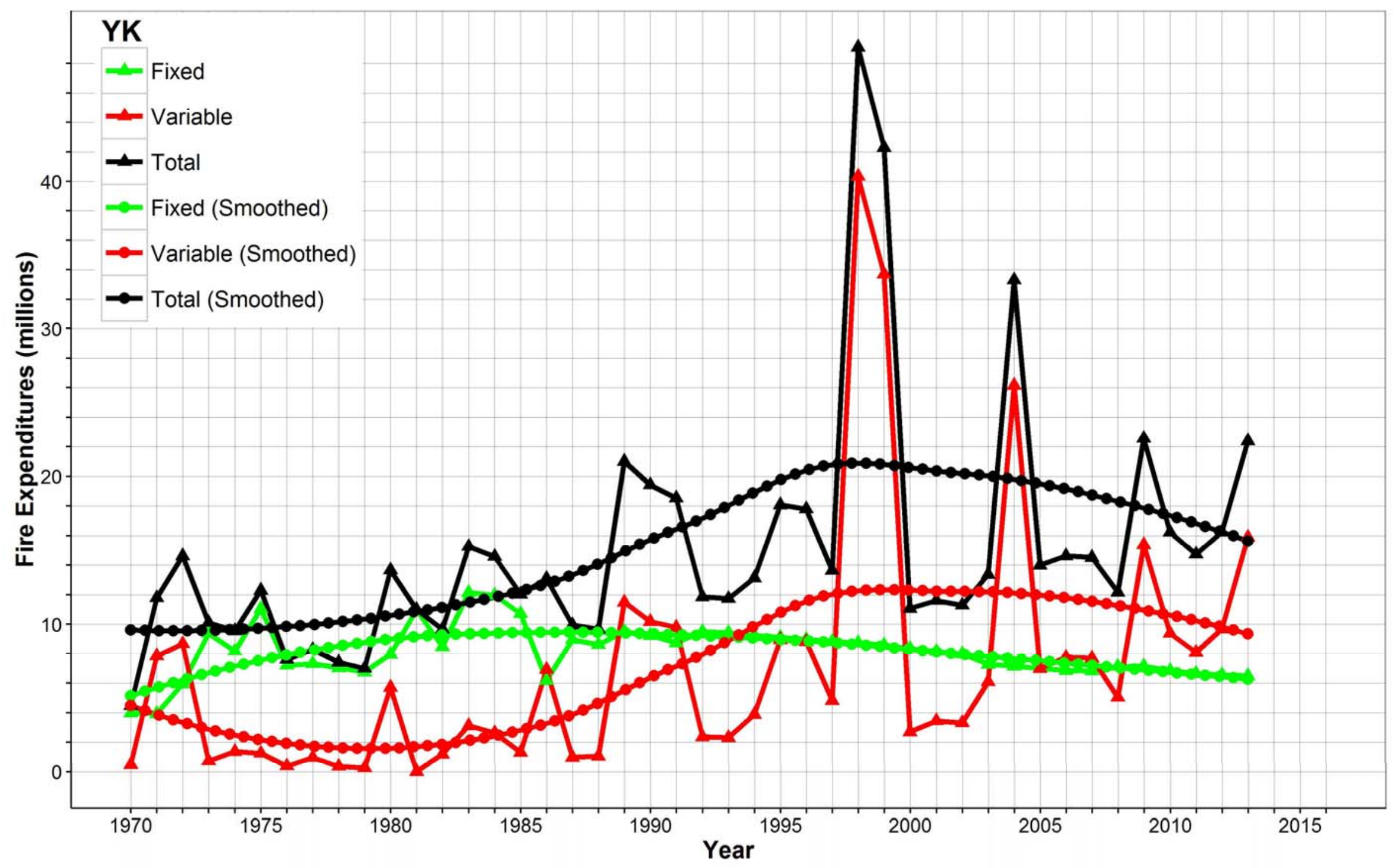

S.Figure 9. Fire management expenditures in the Yukon Territory: $1970-2013$ 


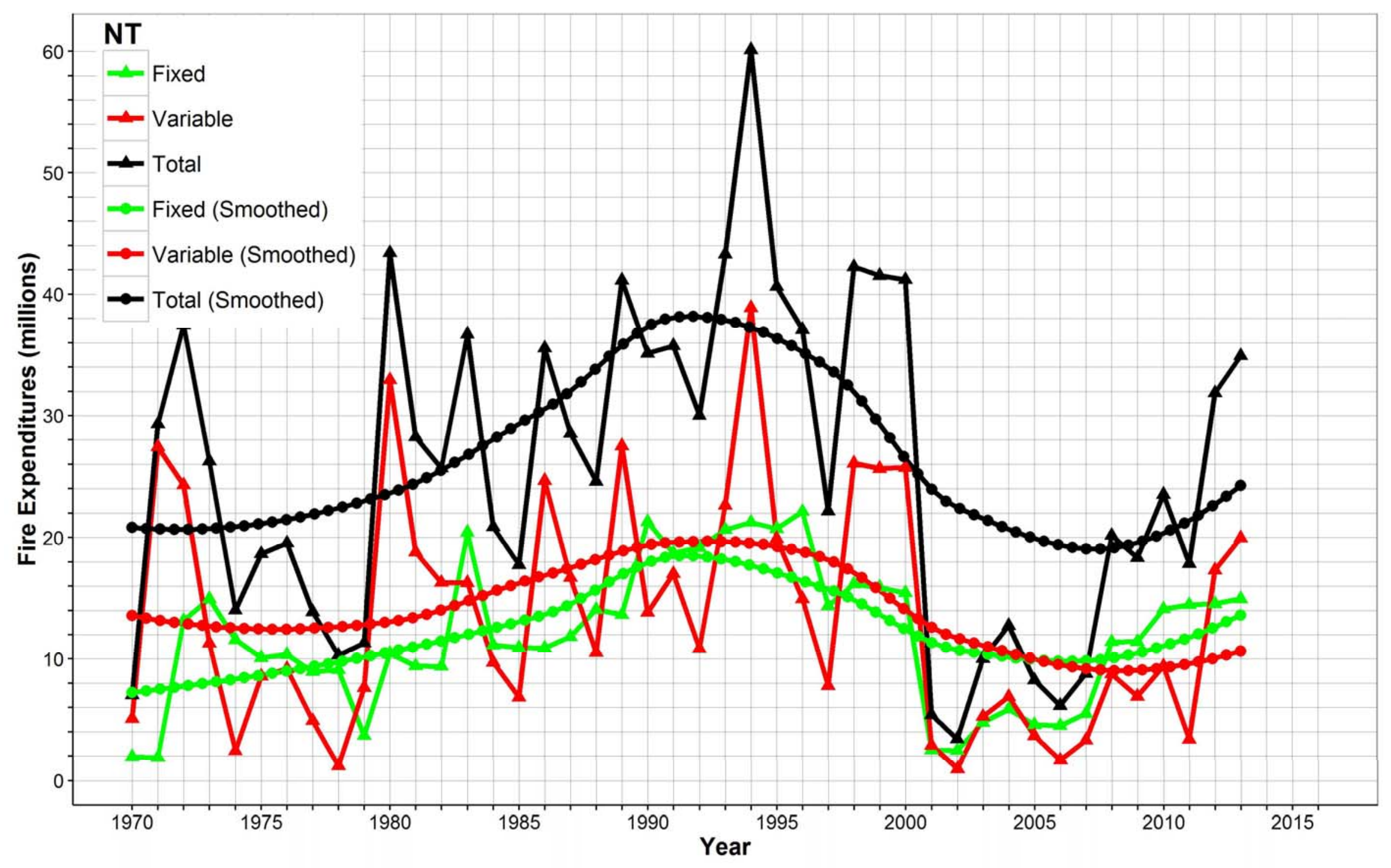

S.Figure 10. Fire management expenditures in the Northwest Territory: 1970 - 2013 


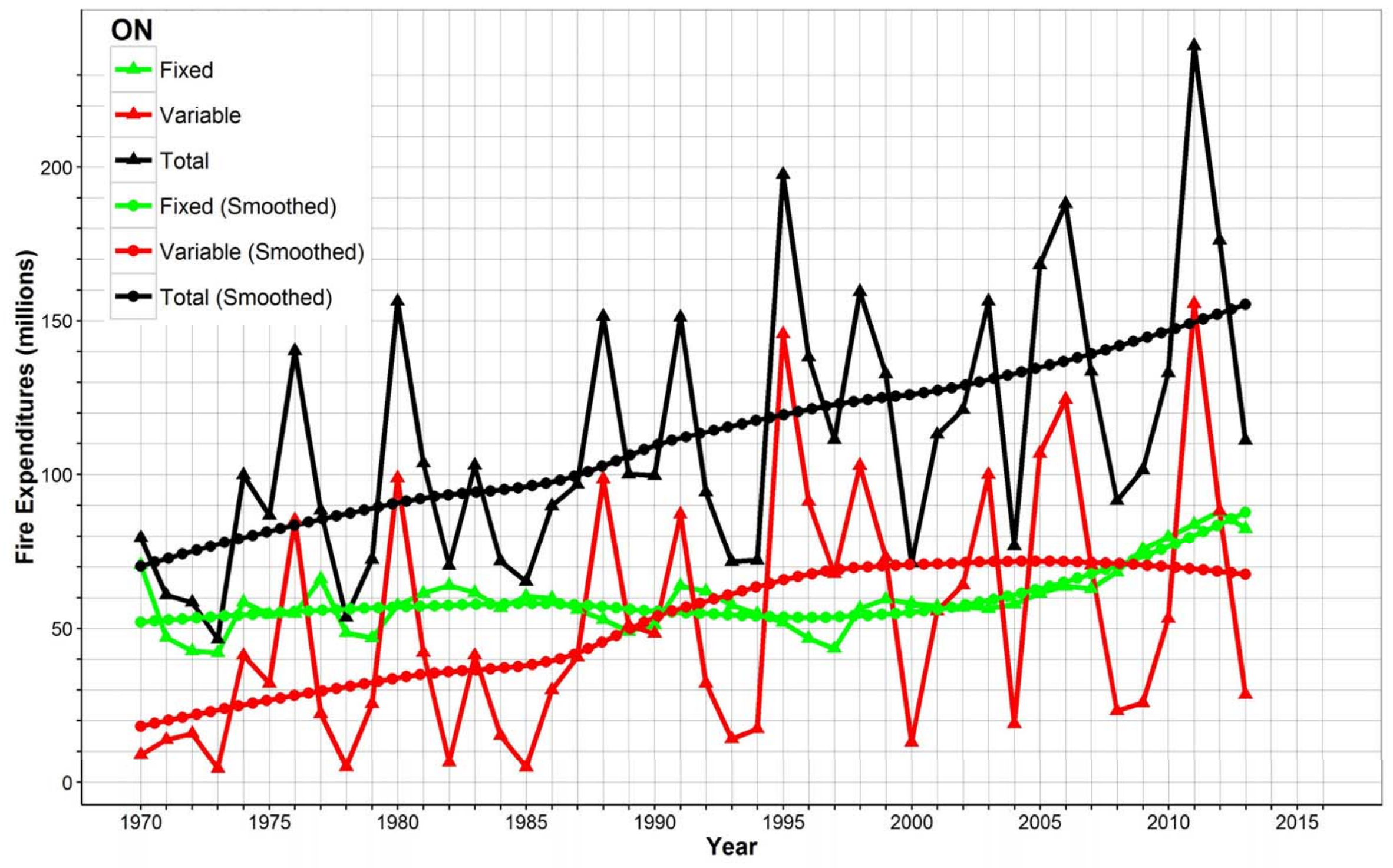

S.Figure 11. Fire management expenditures in the province of Ontario: $1970-2013$ 


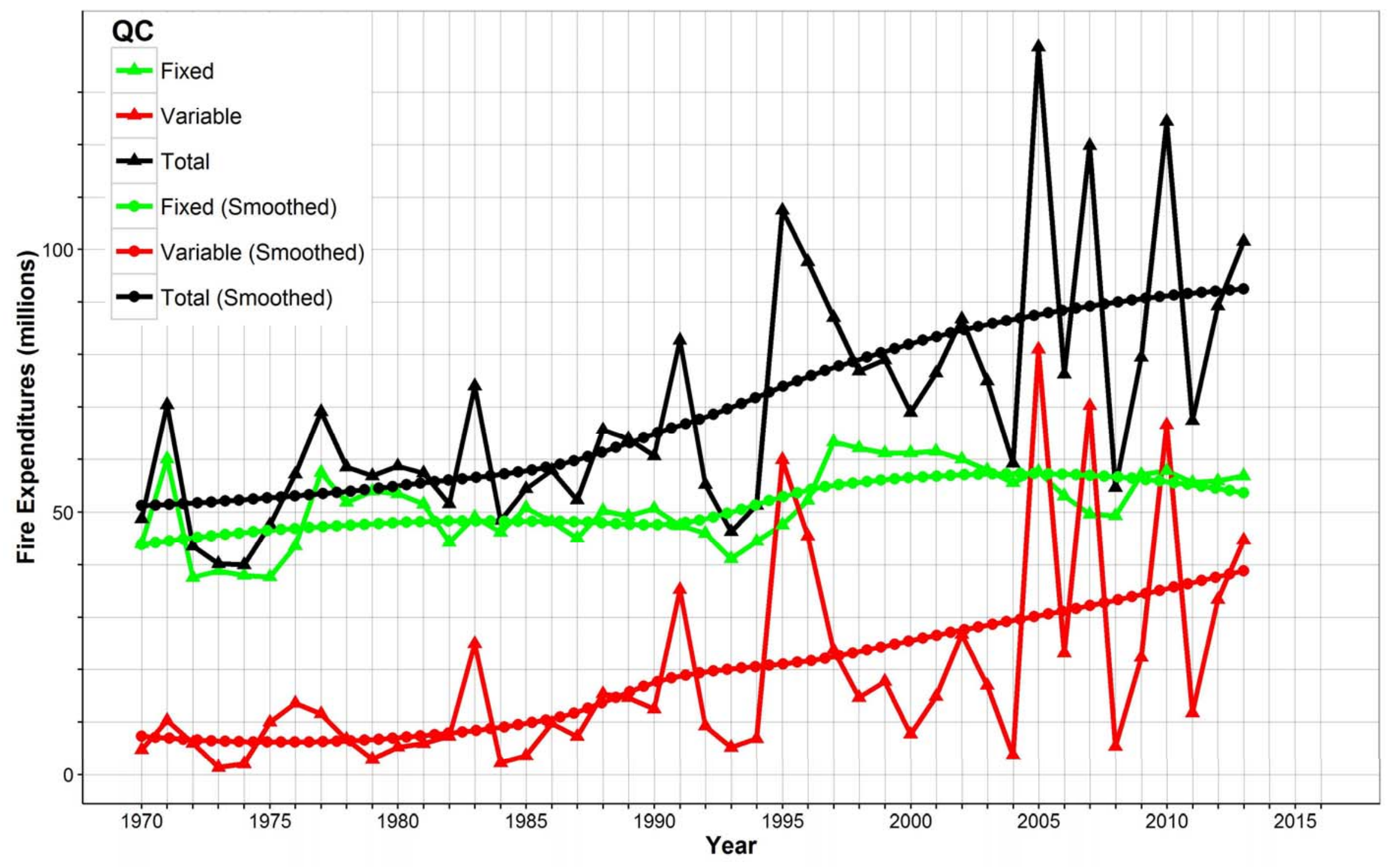

S.Figure 12. Fire management expenditures in the province of Quebec: $1970-2013$ 


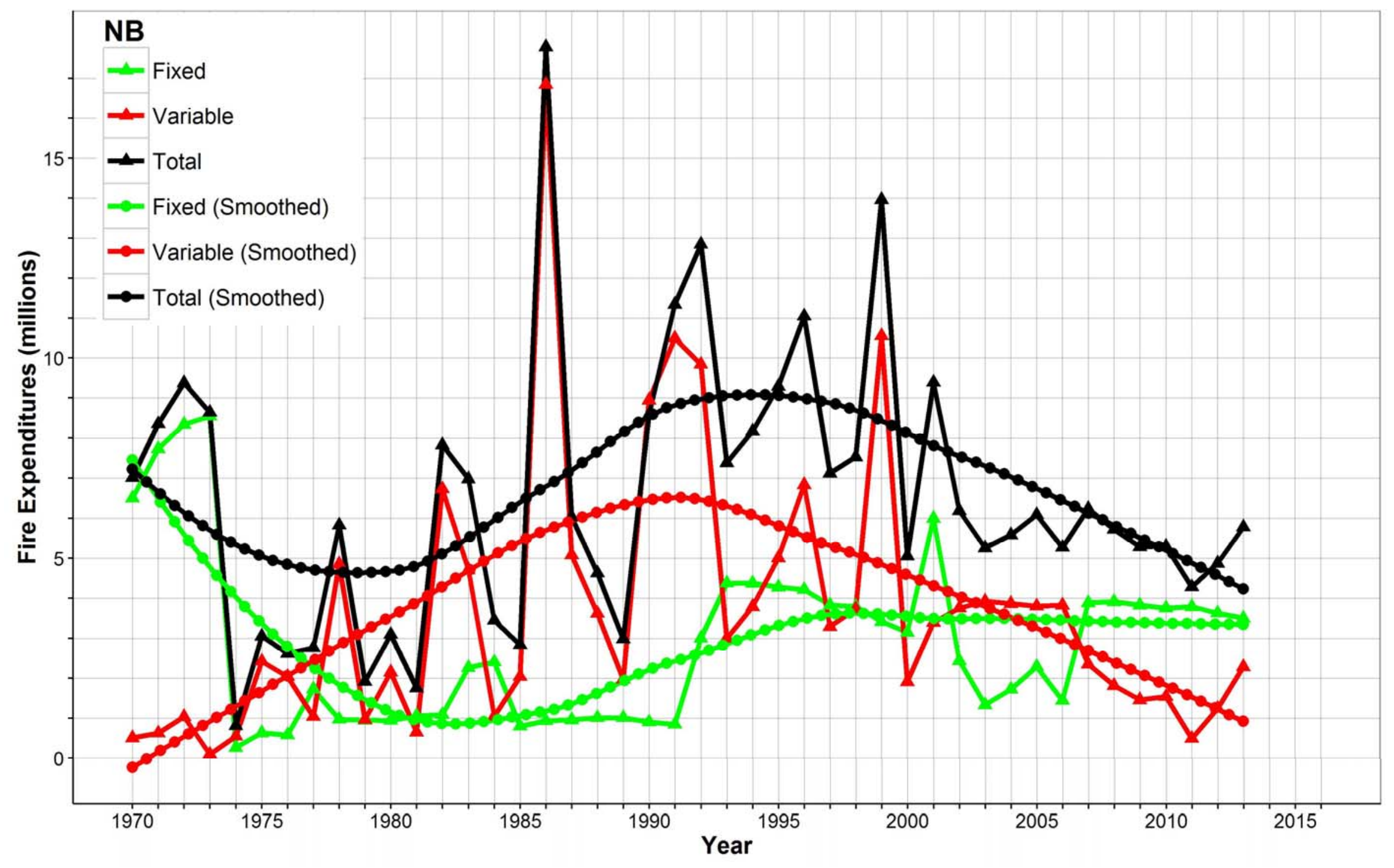

S.Figure 13. Fire management expenditures in the province of New Brunswick: $1970-2013$ 


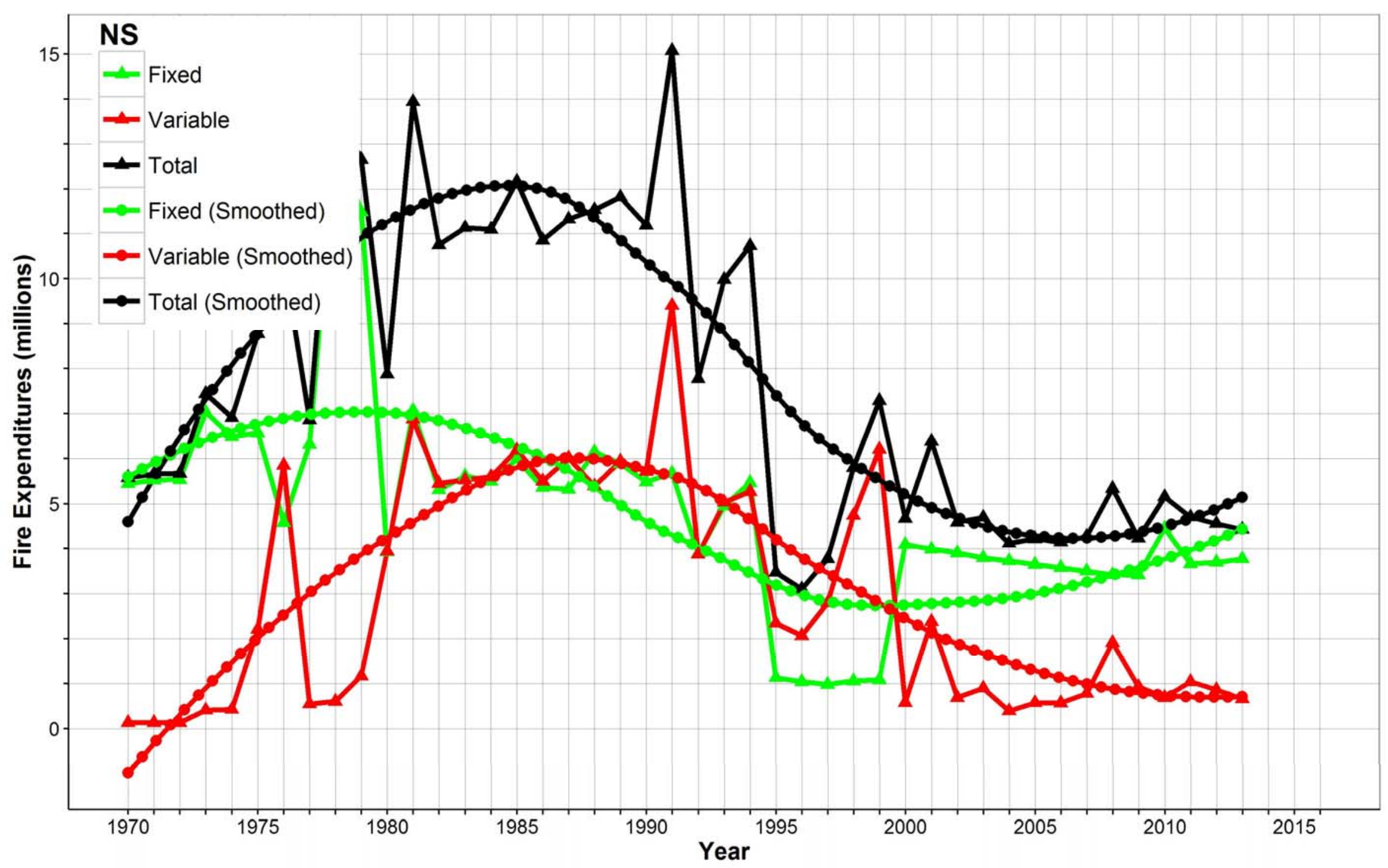

S.Figure 14. Fire management expenditures in the province of Nova Scotia: $1970-2013$

11 


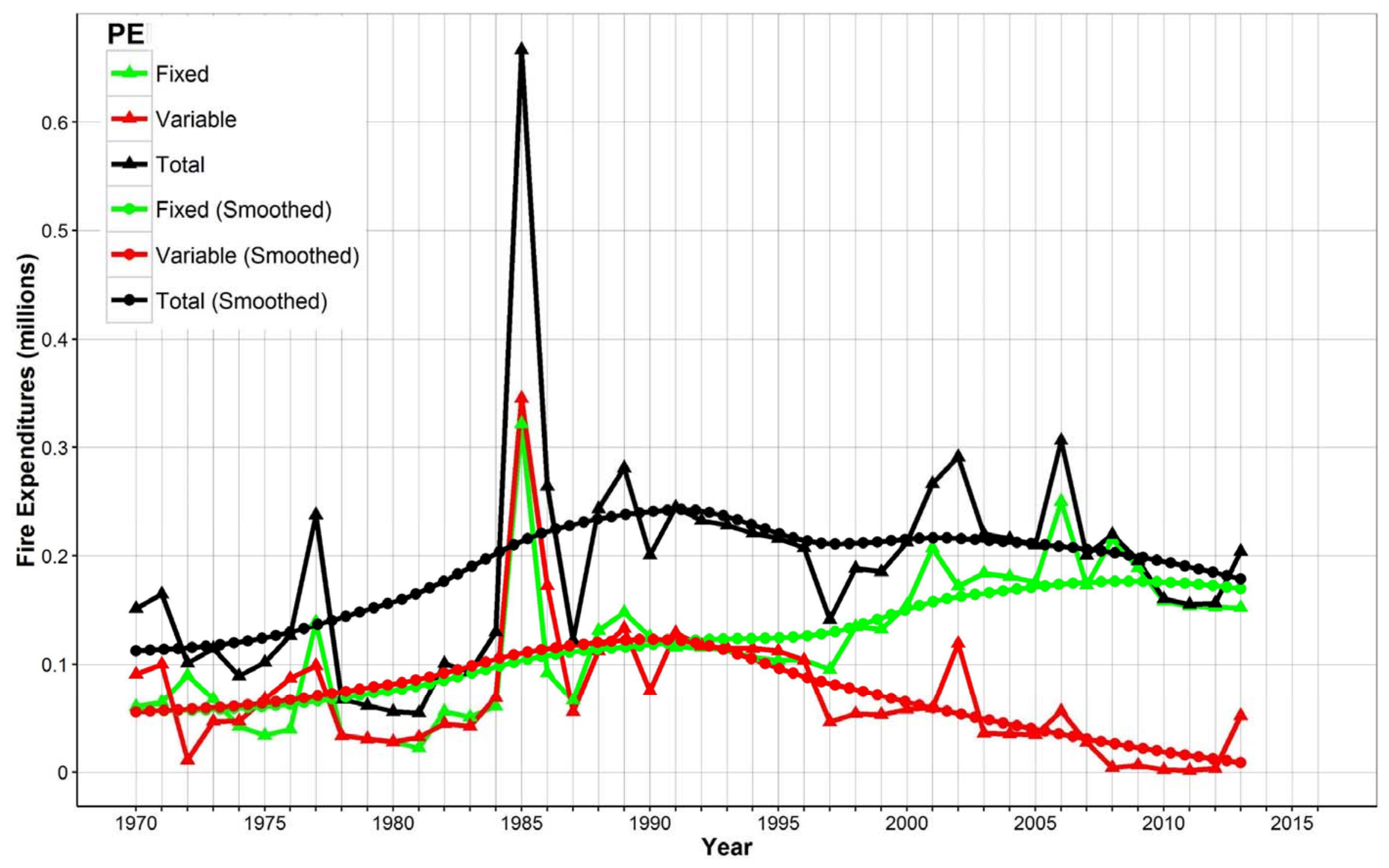

S.Figure 15. Fire management expenditures in the province of Prince Edward Island: 1970 - 2013 


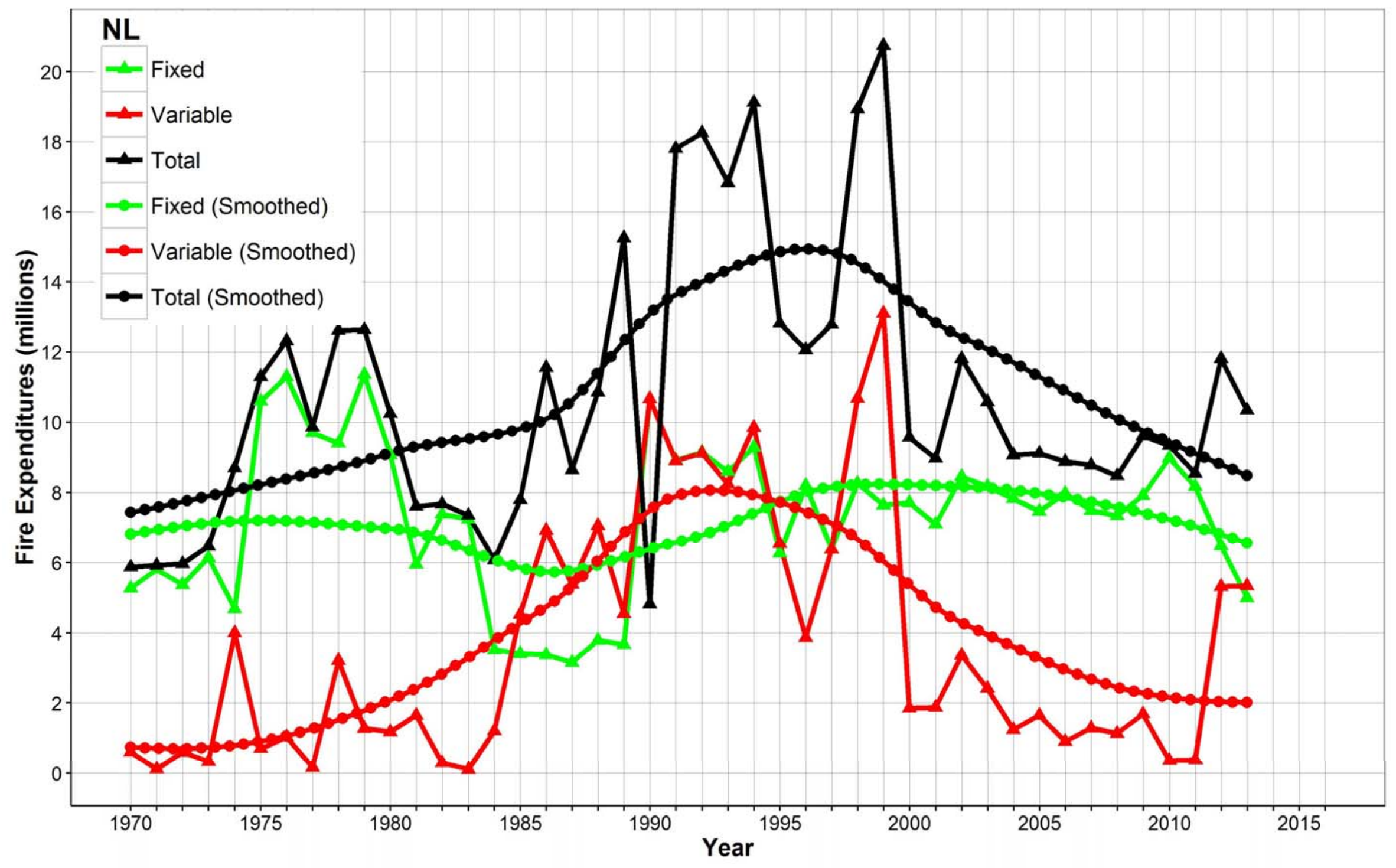

S.Figure 16. Fire management expenditures in the province of Newfoundland and Labrador: 1970 - 2013 


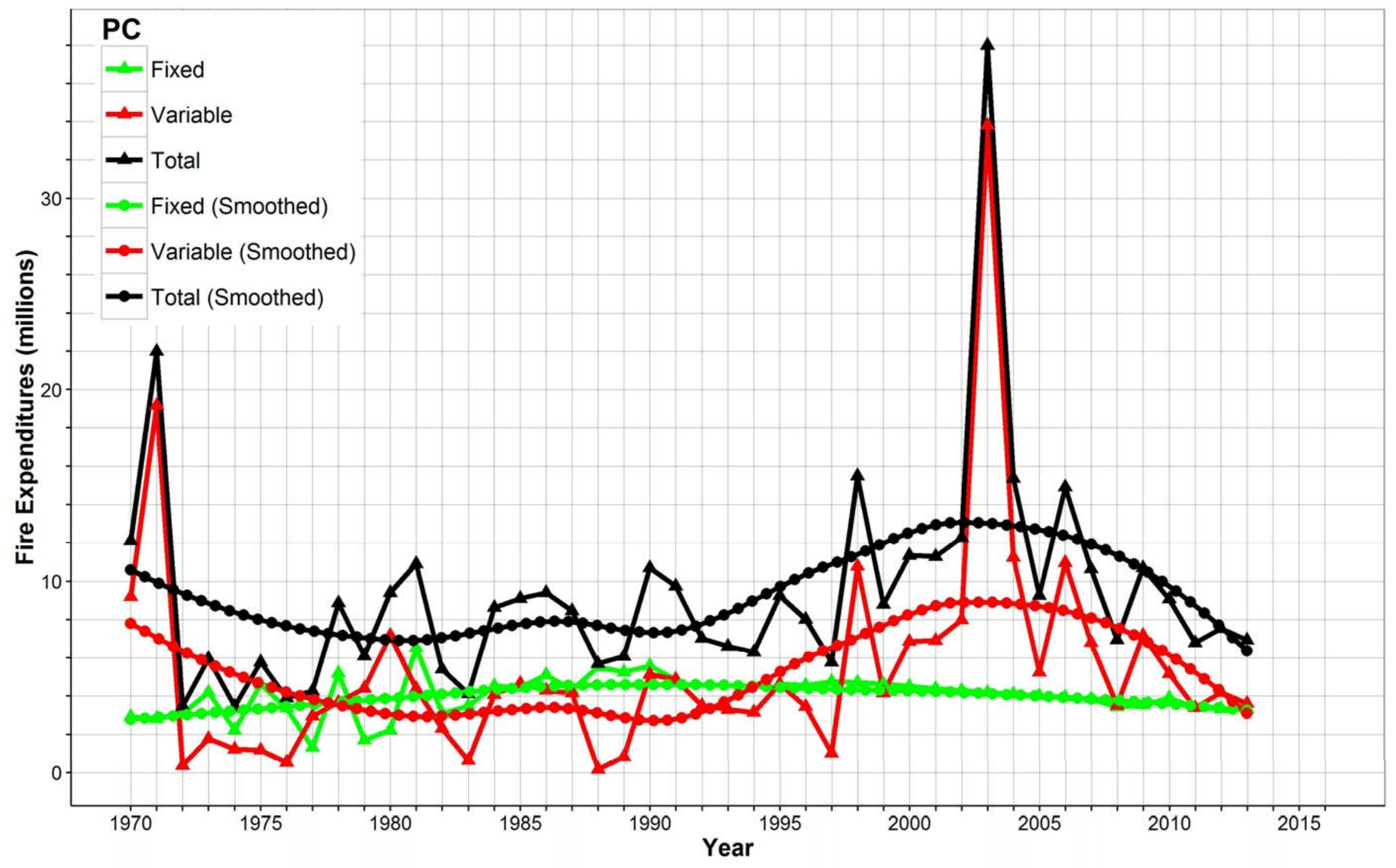

S.Figure 17. Fire management expenditures in Parks Canada: 1970 - 2013 